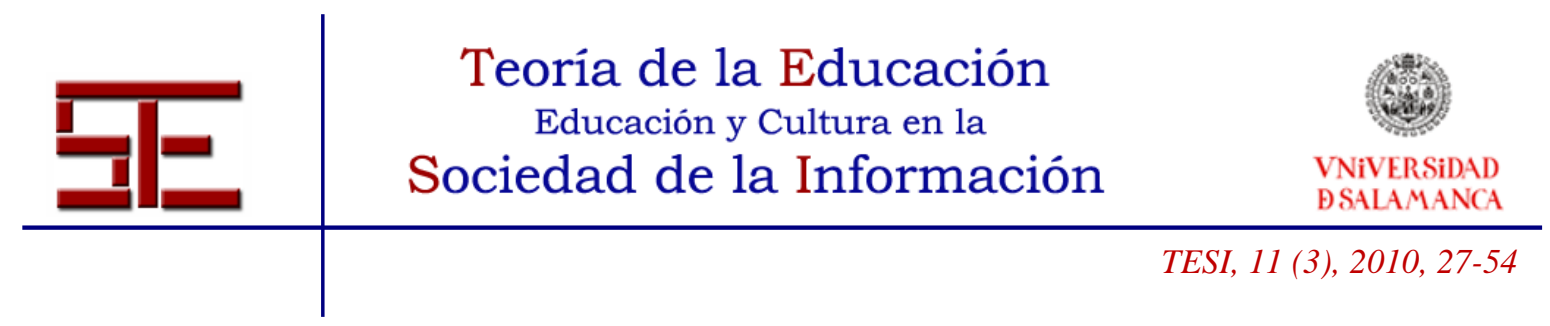

\title{
JUEGOS DE ROL COMO ESTRATEGIA EDUCATIVA: PERCEPCIONES DE DOCENTES EN FORMACIÓN Y ESTUDIANTES DE SECUNDARIA
}

Resumen: Los medios de comunicación han trasladado una imagen negativa sobre los juegos de rol, tanto en Estados Unidos como en España. Asesinatos, suicidios y un cierto grado de psicosis parecen asociados con los juegos de rol, al menos a tenor de las noticias que suelen aparecer en los medios. Curiosamente, estas opiniones no parecen corresponderse con las investigaciones científicas realizadas hasta el momento, ni con las sentencias judiciales dictadas sobre casos relacionados. Esta investigación analiza cuantitativamente las opiniones vertidas mediante cuestionario de 133 jóvenes.

Palabras clave: juego de rol; educación; actitudes; estereotipos.

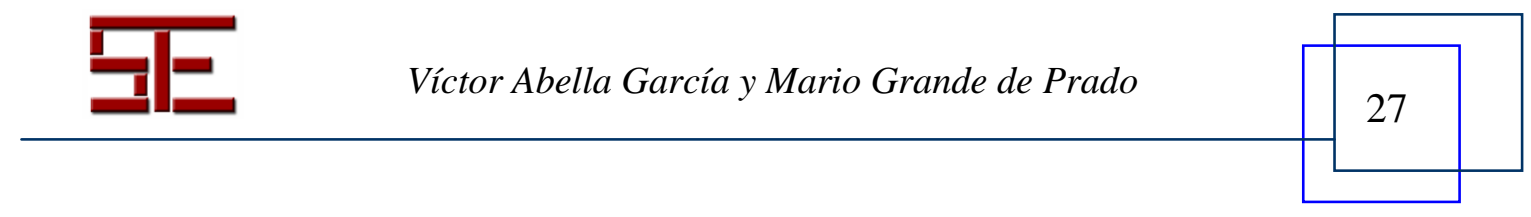




\title{
ROLE AS A STRATEGY GAMES EDUCATION: PERCEPTIONS OF TEACHERS AND STUDENTS IN SECONDARY EDUCATION
}

\begin{abstract}
Mass media have showed a negative image of role playing games in the United States and also in Spain. Murders, suicides and a certain grade of psychosis seems associated with the RPGs, at least on the newspapers. Curiously, these opinions, do not seem to correspond to the scientific investigations realized until now, neither with the legal choices dictated on related cases. This investigation analyzes quantitatively the opinions in a questionnaire of 133 young people.
\end{abstract}

Key words: role playing games; education; attitudes; stereotypes.

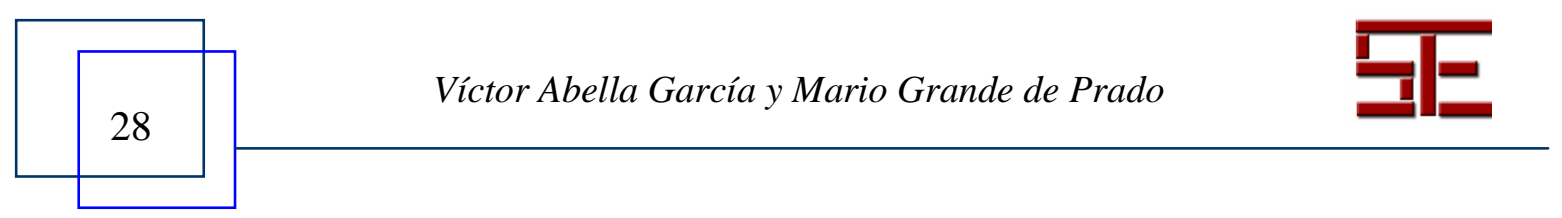




\begin{tabular}{c|c} 
Teoria de la Educación \\
Educación y Cultura en la \\
Sociedad de la Información
\end{tabular}

\title{
JUEGOS DE ROL COMO ESTRATEGIA EDUCATIVA: PERCEPCIONES DE DOCENTES EN FORMACIÓN Y ESTUDIANTES DE SECUNDARIA
}

Fecha de recepción: 13/07/2010; fecha de aceptación: 19/10/2010; fecha de publicación: 30/11/2010

\author{
Víctor Abella García \\ vabella@ubu.es \\ Universidad de Burgos \\ Mario Grande de Prado \\ mario.grande@unileon.es \\ Universidad de León
}

\section{1.- INTRODUCCIÓN: JUEGOS DE ROL Y PRENSA}

Los juegos de rol se encuentran injustamente estigmatizados como una práctica peligrosa o poco recomendable. En Estados Unidos, varias iniciativas los han señalado como peligrosos e incluso responsables de asesinatos y suicidios, sin base científica alguna (Tizón, 2006).

En nuestro país, a mediados de los noventa, dos jóvenes asesinaron a un hombre que encontraron en la calle, al parecer "jugando a rol" en juego creado por ellos denominado Razas. La sentencia judicial no encontró vinculación entre los juegos de rol y el homicidio.

De hecho, en la sentencia se asume el juego de rol (JdR) como un entretenimiento, y el asesinato como una acción más allá de los límites de esta actividad lúdica:

El procesado Javier en fecha no concretada del año 1994 decidió superar tanto la forma lúdica documentada en fichas, como la de la escenificación para materializar en el mundo de la realidad física.

Sentencia del "caso Rosado" . TS 2a , S 25-06-1998, núm. 632/1998, rec. 568/1997.

De hecho, estos juegos han realizado varios intentos (muchos de ellos apoyados en la Red) para darse a conocer y enfrentarse así a la leyenda negra que les rodea, por ejemplo, en España con la edición de guías (VV.AA. 1993) o fuera de nuestro país

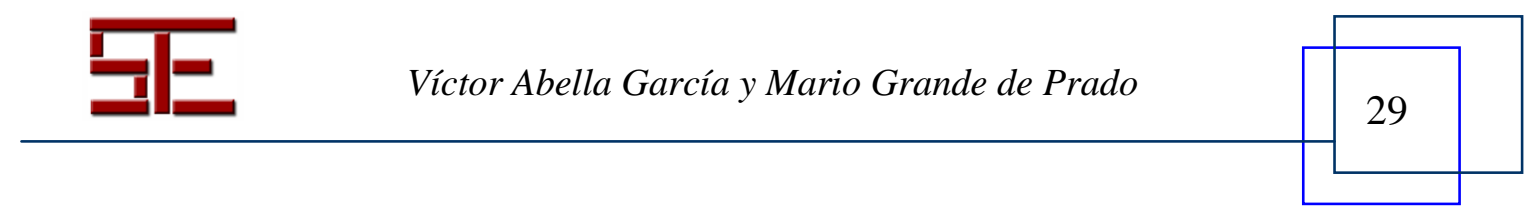




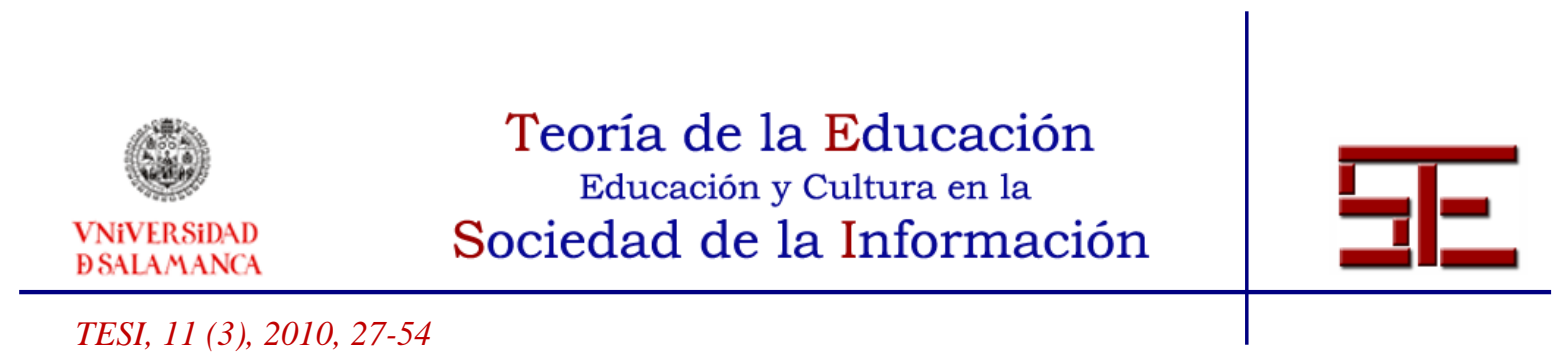

con artículos definiendo los juegos de rol y sus variantes (Hitchens, y Drachen, 2009).

Sin embargo, el juicio mediático ha sido fulminante.

Junto a otros grotescos eventos atribuidos errónea y oportunistamente a los JdR, la imagen de éstos como algo peligroso medró (Tizón, 2006). Tal como puede comprobarse con un mínimo esfuerzo, los periódicos han lanzado hipótesis sobre hechos extraños que posteriormente han resultado no guardar ninguna relación, creando sin embargo una visión tétrica teñida por la desconfianza (acrecentada por diversas películas que explotaban las falsas creencias sobre los JdR) que pervive en la actualidad generando recelo sobre los "incontrolables juegos de rol" (San Sebastián, y San Sebastián, 2004). En la prensa escrita, los comentarios peyorativos (sin base jurídica o científica) han continuado en cuanto han surgido noticias sobre acciones violentas o vandálicas relacionadas con los jóvenes.

Así, por ejemplo, el periódico Metro (21 de marzo de 2007), en la columna de Jesús Montesinos apuntó sobre la desaparición de la estatua de la Virgen de la fachada de la Basílica de la Virgen del Lledó (reapareció rápidamente y sin indicios que relacionen a jugadores de rol con este hecho), afirmaciones como:

\footnotetext{
"No me atrevo a llamarlos ni delincuentes [...] no pueden ser ladrones ni chorizos ni, por supuesto, coleccionistas de arte religioso. Son unos gamberros disfrazados de Rififi jugando al rol, apuesto lo que quieran" y vuelve a la carga dentro del mismo artículo "Ahora hay que coger a los gamberros, por mucho que sean unos simples jugadores de rol. Si estuviera en mi mano cuando los cojan no los denunciaba en el juzgado. Los hacía comparecer en la Plaza Mayor [...] Y luego los mandaba a echar una mano limpiando El Pinar [...]" (Montesinos, 2007).
}

En esta misma línea, el periódico El País nos ha mostrado en su editorial (13 de marzo de 2009) otro ataque hacia los juegos de rol, en este caso en referencia a la matanza perpetrada por un joven alemán en el colegio Albertville de Winnenden (una vez más, nada relaciona este hecho con los juegos de rol):

\footnotetext{
“A pesar de lo esporádico de estas eclosiones de brutalidad, las autoridades europeas han de ser conscientes de que se enfrentan a una patología social potencialmente grave y cuyo único tratamiento de fondo es intensificar las pautas de socialización y de respeto democrático durante el periodo crítico de la educación de los jóvenes que va desde los seis hasta los 26 años. Las fantasías paramilitares, los juegos de rol, el exterminio indoloro de los enemigos en las pantallas y videoconsolas, prestan una canalización fácil y, por desgracia, casi única, a las frustraciones de los jóvenes marginados en la escuela o en su entorno. Es hora de que los sistemas educativos se dediquen a prevenir este tipo de comportamientos atroces" (El País, 13 de marzo de 2009 -Editorial-).
}

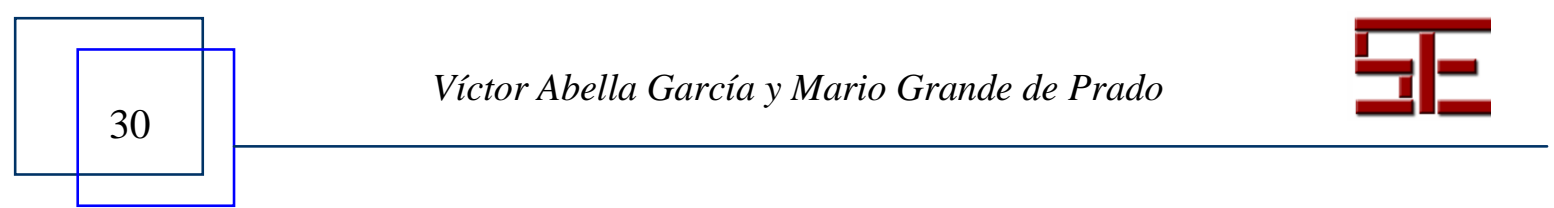




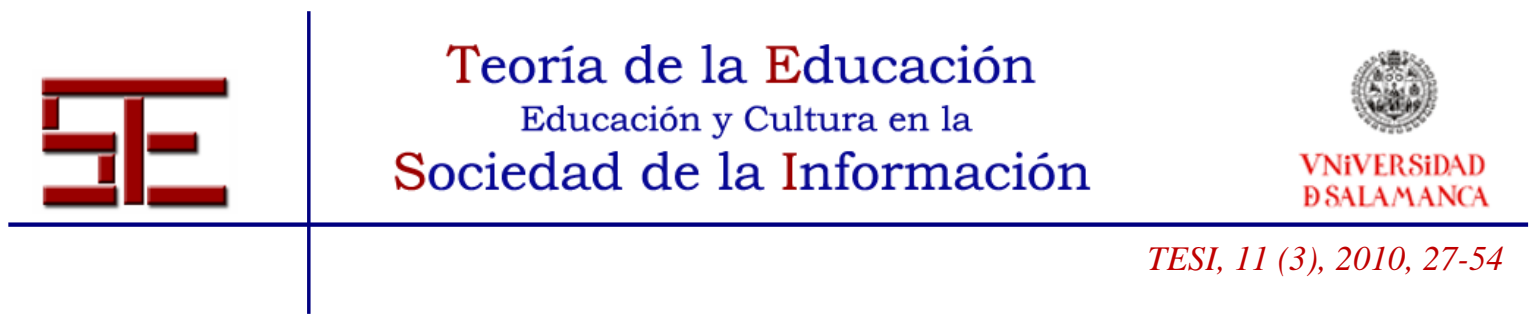

Además de otras consideraciones, como por ejemplo la referencia a la educación de los jóvenes de los seis a los veintiséis -tal vez educación infantil no es importante, o tal vez el autor se plantea aumentar la escolarización obligatoria de los dieciséis a los veintiséis- el artículo plantea que los juegos de rol son una de las causas de "una patología social potencialmente grave", siendo así los JdR objeto de un nuevo ataque gratuito.

Dada la presión mediática, algunos conocedores de lo que realmente era un juego de rol han expresado su opinión en distintos manifiestos defendiendo esta afición (p. e. Pérez Reverte, 1994).

Autores, asociaciones y editoriales publicaron diversos comunicados (disponibles online en http://dreamers.com/defensadelrol/). Probablemente lo más reseñable para describir esta época en relación a los juegos de rol fue una paulatina bajada de ventas y una menor captación de nuevos jugadores, que se intentó contrarrestar con jornadas abiertas y la creación de una asociación nacional, Homo Ludens (www.homo-ludens.com).

\section{1.- ¿Qué han dicho al respecto las investigaciones académicas sobre los juegos de rol?}

Dado que la base de la ciencia se expresa mediante números, vamos a tener en cuenta una reflexión matemática. John Allen Paulos (1988), en una obra sobre analfabetismo matemático, emplea la polémica surgida en EE.UU. sobre la relación entre juegos de rol (Dungeons and Dragons, el decano de los JdR, en concreto) y suicidios como un ejemplo de una falacia de base amplia en matemáticas, al citarse sólo números absolutos de suicidios sin relacionarlos con la totalidad de la población del grupo de jugadores. Realizando el análisis correcto, se llegaría estadísticamente a que la tasa de suicidio es diez veces menor en los jugadores de rol que entre los no jugadores.

a) Entre las investigaciones psicológicas realizadas sobre personalidad, podemos citar:

$>$ Simón $(1987,1998)$ ha realizado investigaciones sobre la estabilidad emocional, basándose en los resultados del conocido cuestionario $16 \mathrm{PF}$ de Cattel, de jugadores novatos y veteranos de dos de los juegos más populares. Los resultados muestran que son individuos normales.

$>$ Rosenthal, Soper, Folse y Whipple (1998) comparan el perfil de jugadores de rol

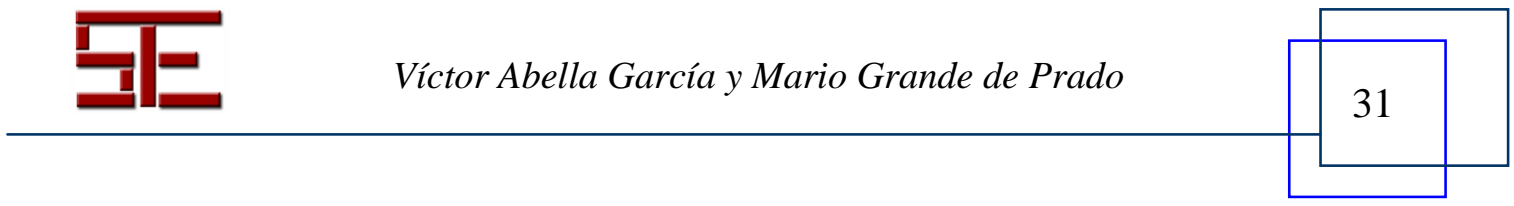




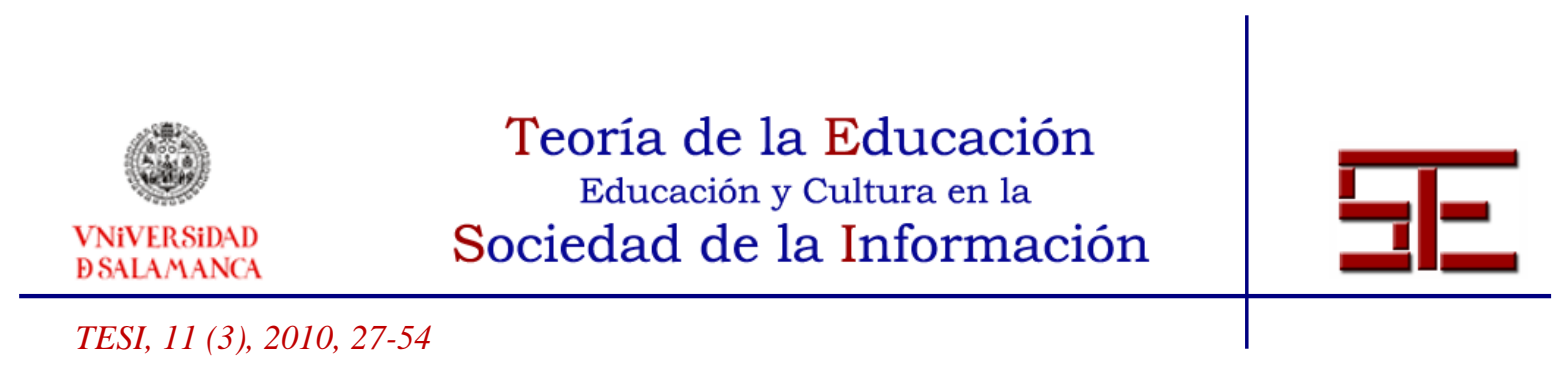

y guardias nacionales. La comparación no deja de ser interesante al contraponer el perfil de los jugadores con el de una de las profesiones que debería tener profesionales más estables (no en vano pueden enfrentarse a situaciones complicadas y van armados). Empleando una escala de neuroticismo y variables demográficas, comprueban que no hay diferencias significativas en neuroticismo. Observan que los jugadores de rol son más soñadores y que el estereotipo de los jugadores como adolescentes emocionalmente inmaduros no se ve refrendado por la investigación, siendo el jugador típico un varón con tantos amigos cercanos como el guardia nacional medio.

$>$ Carter y Lester (1998) muestran que los jugadores no tienen tendencias suicidas depresión, psicoticismo, extraversión o neuroticismo por encima de la norma.

$>$ DeRenard y Kline (1990) no encuentran diferencias entre jugadores y no jugadores (excepto en el área de "distanciamiento cultural", que refleja desinterés por las formas de ocio populares).

$>$ Abyeta y Forest (1991) afirman que los jugadores de rol tienen menores tendencias criminales que el resto de la población.

$>$ Douse y McManus (1993) realizan un estudio incluyendo a jugadores de rol por correo, y sus resultados muestran diferencias no relevantes entre jugadores y no jugadores.

$>$ En España, el estudio más relevante es ofrecido por el Colegio Oficial de Psicólogos de Madrid en el año 1999 a instancias del Defensor del Menor de Madrid (Jodar y Vecina Jiménez, 1999). Con el título "Efectos psicosociales de los juegos de rol en el desarrollo social y cognitivo de los menores", sus conclusiones se resumen en:

"Los resultados obtenidos en este estudio permiten concluir que el desarrollo social y cognitivo de los adolescentes que juegan al rol es similar al que presentan los menores que no practican este tipo de juegos, ya que la variable Juego de rol no influye en ninguna de las variables que miden dicho desarrollo. Únicamente puede constatarse una excepción en el caso de las mujeres, donde parece que jugar al rol influye positivamente, reduciendo la ansiedad social y la timidez" (Jodar y Vecina Jiménez, 1999, 526).

b) Sobre los aspectos educativos:

Dentro del ámbito nacional:

$>$ En el artículo "Los Juegos de Rol: Hacia una propuesta pedagógica" (Giménez ,2003) se indican algunos de los beneficios que podrían tener los JdR:

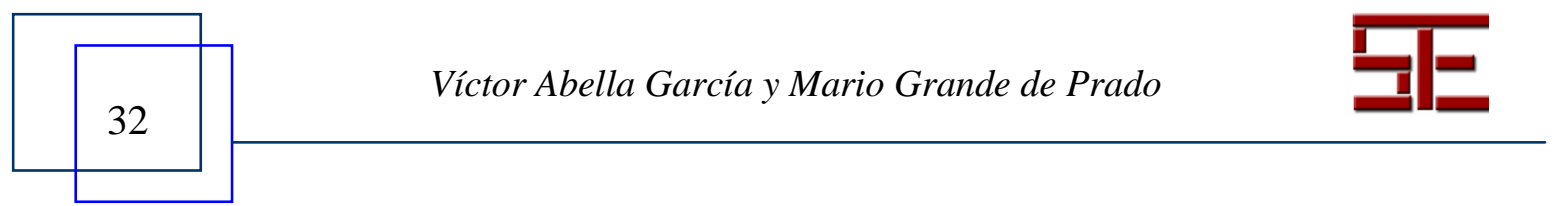




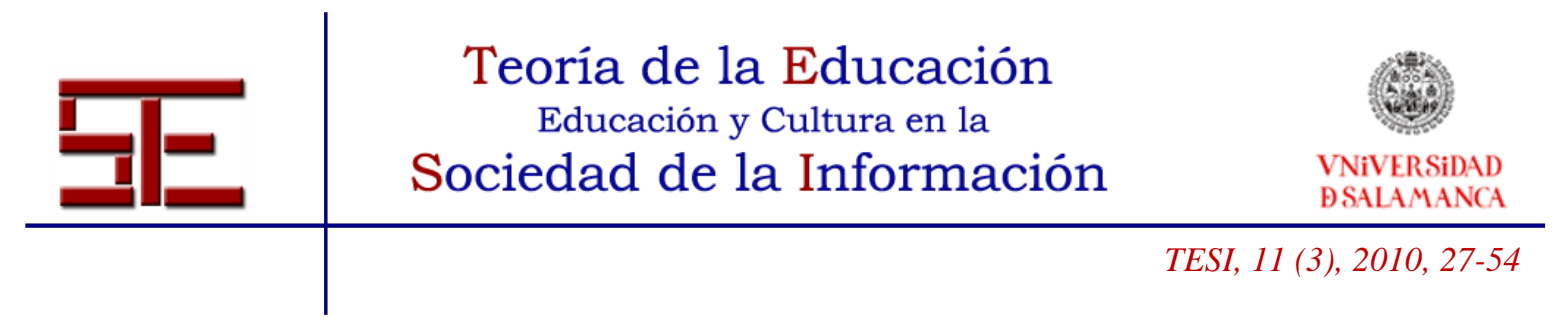

○ En educación (memoria, lectura, aprendizaje significativo...)

○ En determinadas actitudes (empatía, tolerancia, sensibilización...).

- Salud mental.

$>$ En otro artículo, Joan Ortiz Castells (2003) defiende los juegos de rol como una vía lícita de aprendizaje, creativa, motivadora y cita varios valores de los juegos de rol en contraposición a los de la institución educativa.

$>$ Sobre las posibilidades en el fomento de la lectura y la literatura (Calleja, 1995) parece clara su capacidad para motivar a los alumnos y promocionar la lectura.

$>$ Nuevamente, en el estudio encargado por el Defensor del Menor de la Comunidad de Madrid (Jodar y Vecina, 1999), nos encontramos en las recomendaciones con referencias a talleres educativos sobre juegos de rol fomentados por instituciones públicas en aspectos como educación para la salud, la convivencia... y se sugiere que pueden ser una "valiosa herramienta de intervención social con adolescentes para la promoción activa de actitudes y conductas positivas" (Jodar y Vecina Jiménez, 1999, 527).

A nivel internacional, continuando con la educación, las posibilidades de estos juegos se han comentado en relación a:

$>$ Zayas y Lewis (1986): modificación de problemas de conducta, con niños de 8 y 9 años, planteándoles escenarios en los que la cooperación permite resolver un situación conflictiva aprovechando las destrezas individuales.

$>$ Malcolm (1994) propone trabajar las dificultades de aprendizaje en la lectoescritura empleando como herramienta los JdR.

$>$ Holinsworth (1995) reflexiona sobre moralidad y ética tratados mediante JdR, (toma de decisiones, consecuencias, valores...).

$>$ Hübner (1995) aporta estrategias educativas para el uso de juegos de rol en prevención de la violencia juvenil en una publicación editada por el Gobierno alemán.

$>$ Phillips (1995) resalta las ventajas del uso de los juegos de rol y el aprendizaje del inglés como segunda lengua, empleando distintas estrategias, dando pautas de observación....

$>$ Oliver (1995) propone eliminar estereotipos sexuales mediante juegos de rol.

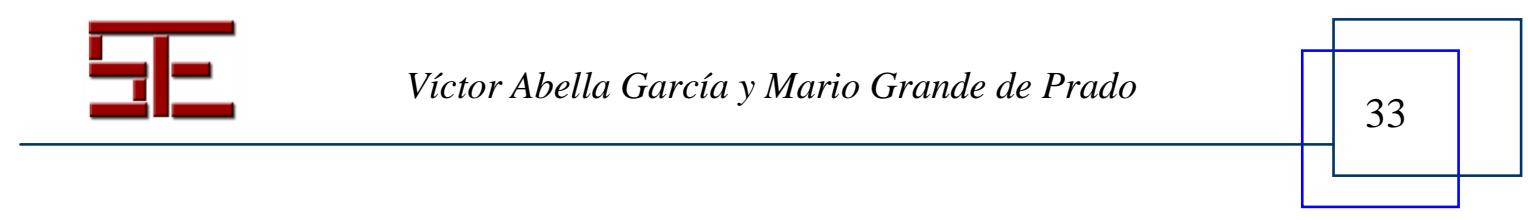




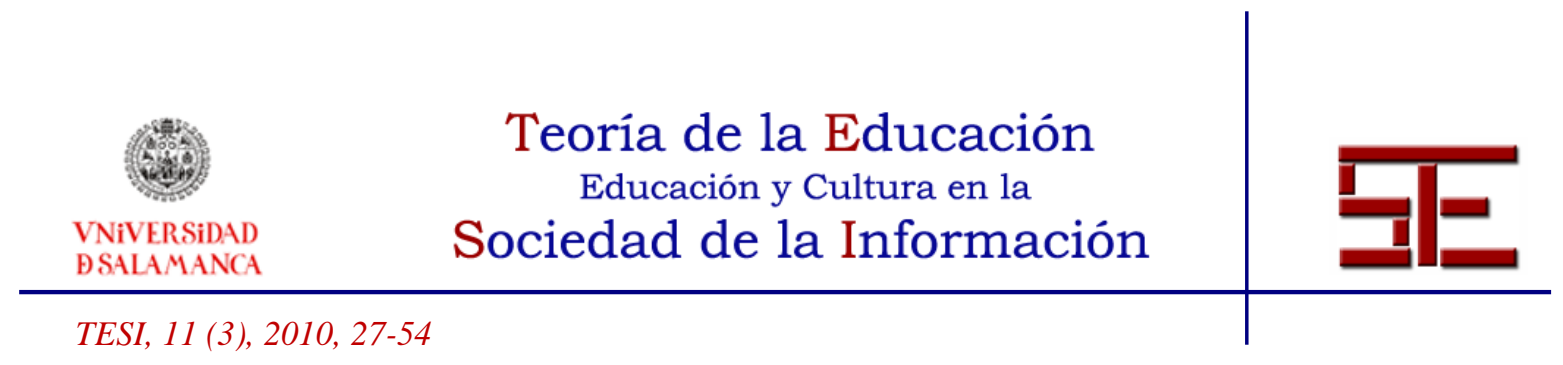

Resumiendo, los estudios psicológicos muestran que los jugadores de rol son individuos con personalidades normales y las propuestas pedagógicas apuntan sus posibles ventajas, ya que, como hemos visto, estos juegos pueden ser una herramienta interesante.

\section{2.- Percepciones de los jugadores}

¿Cómo se perciben los jugadores de rol? ¿Qué opinan de su afición?

En un pequeño estudio realizado en una treintena de aficionados a los juegos de rol (Amante, 2003) se reflexiona sobre su mala fama y su relación con los medios de comunicación, que reproducimos de manera sintética:

"Una de las mayores causas que han dado lugar a la mala fama del rol es el tratamiento en los medios de comunicación: quince de los treinta y cuatro encuestados escogieron en la pregunta catorce la opción C: la fama del rol se debe a los medios de comunicación. Son muchas las agresiones que se han hecho al rol desde los medios (...) se acaba cayendo en errores tan bestiales escuchados en los medios como estos:

"Inquietante reunión en Villareal de jugadores de rol de toda España", (...) "no es extraño que esos juegos delirantes abunden en propósitos racistas y nazis"... son sólo algunos fragmentos sacados de dos noticias, una del diario Las Provincias y otra del periódico El Mundo”. (Amante, 2003).

Dentro de esta pequeña encuesta, los jugadores de rol señalan que estos juegos:

$>$ Fomentan la lectura.

$>$ Estimulan la imaginación.

$>$ Desarrollan la dinámica de grupo.

$>$ No crean adicción a los videojuegos.

$>$ Rechazan la idea de que los juegos de rol forman caracteres agresivos.

$>$ Aumentan la tolerancia (este aspecto lo señalan especialmente los jugadores de mayor edad).

$>$ No incitan al suicidio y niegan que el rol produzca comportamientos agresivos o patologías psicológicas.

Resulta interesante también la siguiente afirmación:

"Ningún encuestado considera que la fama del rol se deba a un fomento de la agresividad, el $44,1 \%$ lo achacan a los medios y el $47 \%$ a la ignorancia".

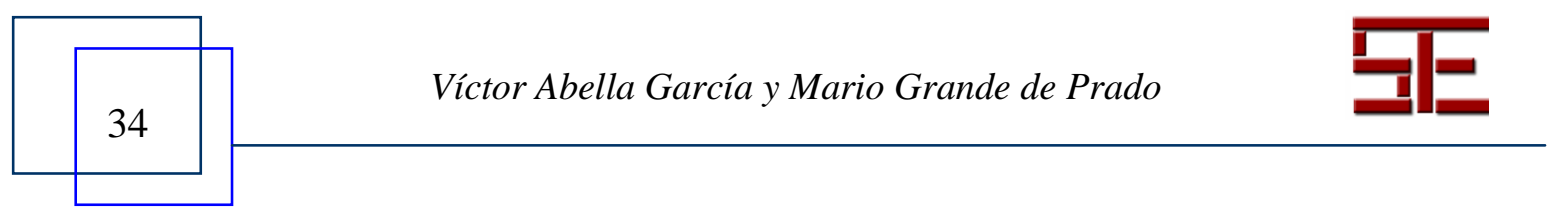




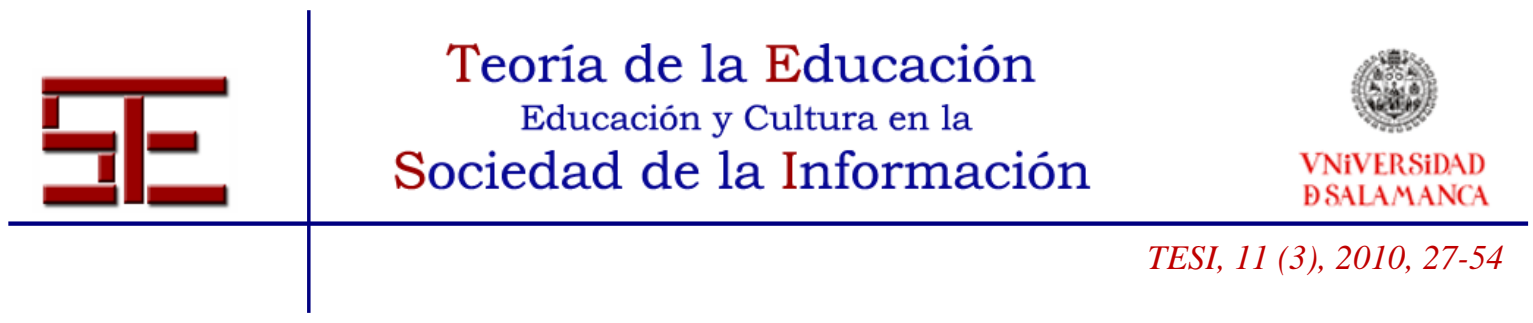

Esta afirmación se puede complementar con una encuesta online realizada en la página En defensa de los juegos de rol (http://dreamers.com/defensadelrol/). En dicha encuesta de las casi 2.700 aportaciones de jugadores, dos tercios valoran como negativo el trato de los mass media hacia los JdR.

Por tanto, los jugadores de rol consideran su afición como algo sano e incluso positivo, considerando además que son tratados injustamente por los mass media.

Podemos concluir, por tanto, que los juegos de rol:

- están mal vistos por la prensa,

- presentan ventajas psicológicas y educativas contrastadas científicamente,

- los jugadores de rol perciben su actividad como sana y se sienten estigmatizados por los mass media.

A continuación, partiendo de estos hechos, analizaremos las percepciones de jóvenes jugadores y no jugadores, alumnos de la ESO y universitarios para comprobar si el impacto de los medios de comunicación ha generado fuertes estereotipos en los jóvenes. ¿Qué opinión tendrán jóvenes interesados en aspectos educativos como los alumnos de Magisterio? ¿Y los alumnos de ESO? Estos aspectos son los que intentamos explorar en nuestra investigación.

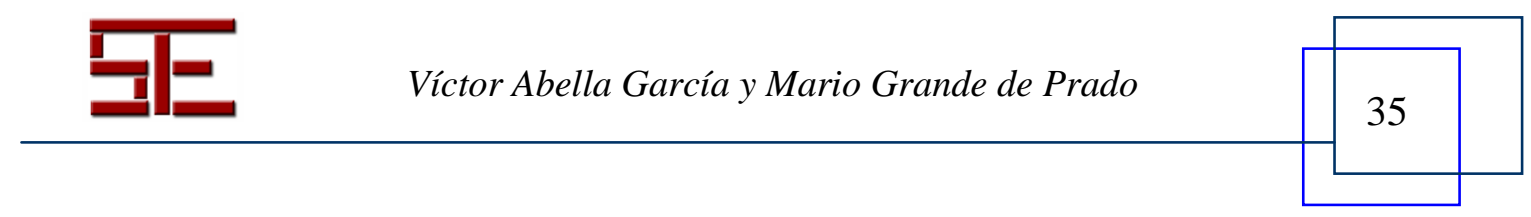




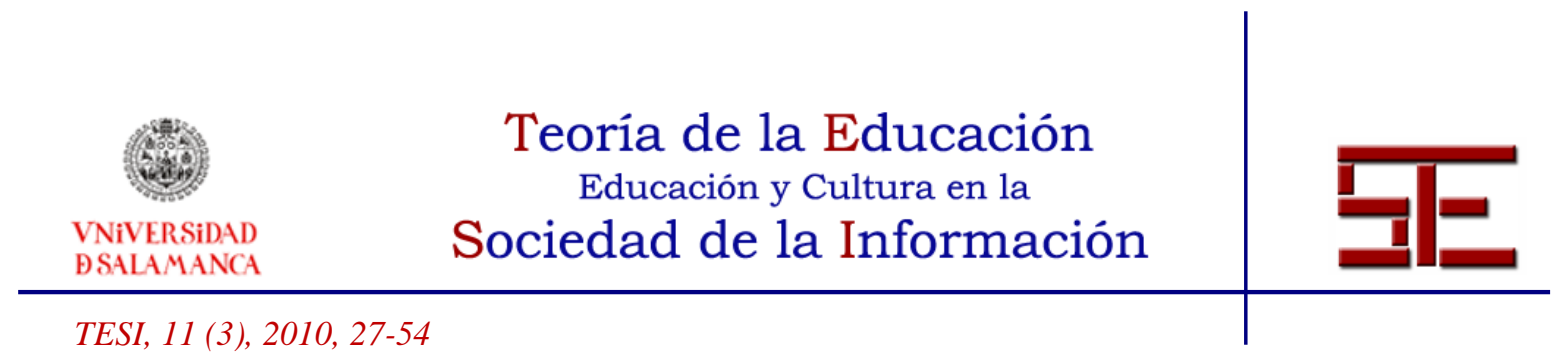

\section{2.- MÉTODO}

\subsection{Objetivo de la investigación}

La intención, por tanto, de esta investigación es observar la opinión de los jóvenes sobre los juegos de rol, especialmente en base a algunas variables como sexo, edad, el hecho de haber jugado a rol... y dentro de este grupo nos interesa especialmente la opinión de los jóvenes interesados en la Educación (alumnos de Magisterio), dado que son los que en un futuro podrían emplear con intención pedagógica los juegos de rol. Para ello se ha recogido en un cuestionario cerrado de dieciséis preguntas la opinión de 133 jóvenes, siendo dicho cuestionario anónimo. Los resultados obtenidos se muestran a continuación.

\subsection{Muestra}

La muestra estaba compuesta por un total de 133 participantes, de los cuales $94(70,7 \%)$ eran estudiantes universitarios y 39 (29,3\%) estudiantes de cuarto curso de Educación Secundaria Obligatoria. La edad de los participantes comprendía entre los 15 y los 38 años, siendo la edad media 18,76 (S.D. $=3,43$ ). En cuanto a la distribución por sexos, un $25,6 \%(\mathrm{n}=35)$ del total de la muestra eran varones, mientras que el $74,4 \%(\mathrm{n}=98)$ restante eran mujeres.

\subsection{Instrumentos}

Se elaboró un cuestionario cerrado por el que a partir de 16 preguntas, siete en una escala tipo Likert de cuatro puntos, ocho de respuesta múltiple y una de respuesta Sí/No (“Si no has jugado nunca ¿te animarías a probarlo?”). Este cuestionario quiere recoger la percepción referente a los juegos de rol, sus jugadores, ventajas, desventajas, fuentes de información...

El cuestionario es anónimo; se pide a los sujetos que indiquen como datos personales: edad, ocupación y sexo.

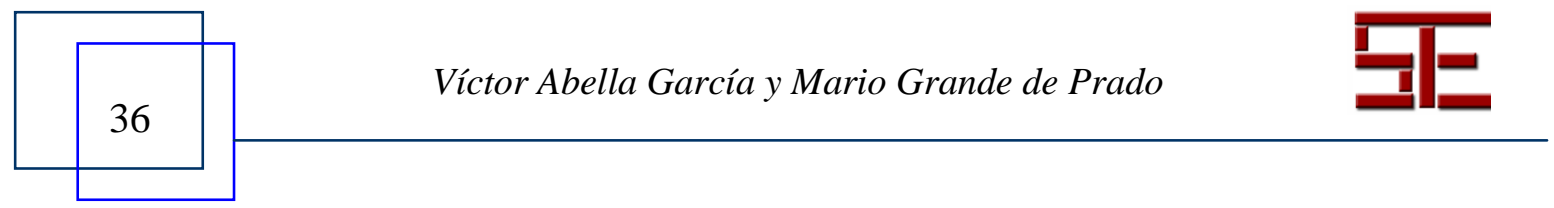




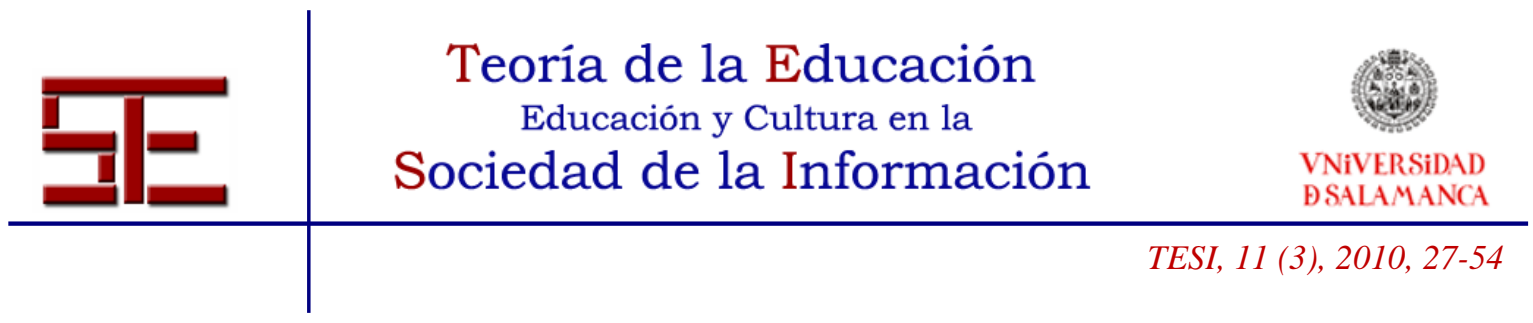

\subsection{Procedimiento}

Se ha recogido en un breve cuestionario cerrado de dieciséis preguntas la opinión de 133 jóvenes, siendo dicho cuestionario anónimo. Se solucionaron las dudas planteadas y se explicaron brevemente las diferencias entre juego de rol y videojuego de rol, dejando un lapso de respuesta y reflexión. El tiempo empleado en total no superó los treinta minutos por grupo. Los grupos fueron escogidos por accesibilidad, y pertenecen a dos clases de $4^{\circ}$ E.S.O. de un centro concertado urbano de León, y a tres especialidades de primer curso de Magisterio de la Universidad de León, realizando el cuestionario en el curso 08/09.

\section{3.- RESULTADOS}

\subsection{Frecuencia de juego}

Del total de encuestados la mayoría manifiestan no haber jugado $(75 \%)$. El resto de sujetos $(25 \%)$ manifiestan haber jugado aunque en diferente grado, siendo sólo un participante el que considera que juega de una forma bastante habitual (Figura 1).

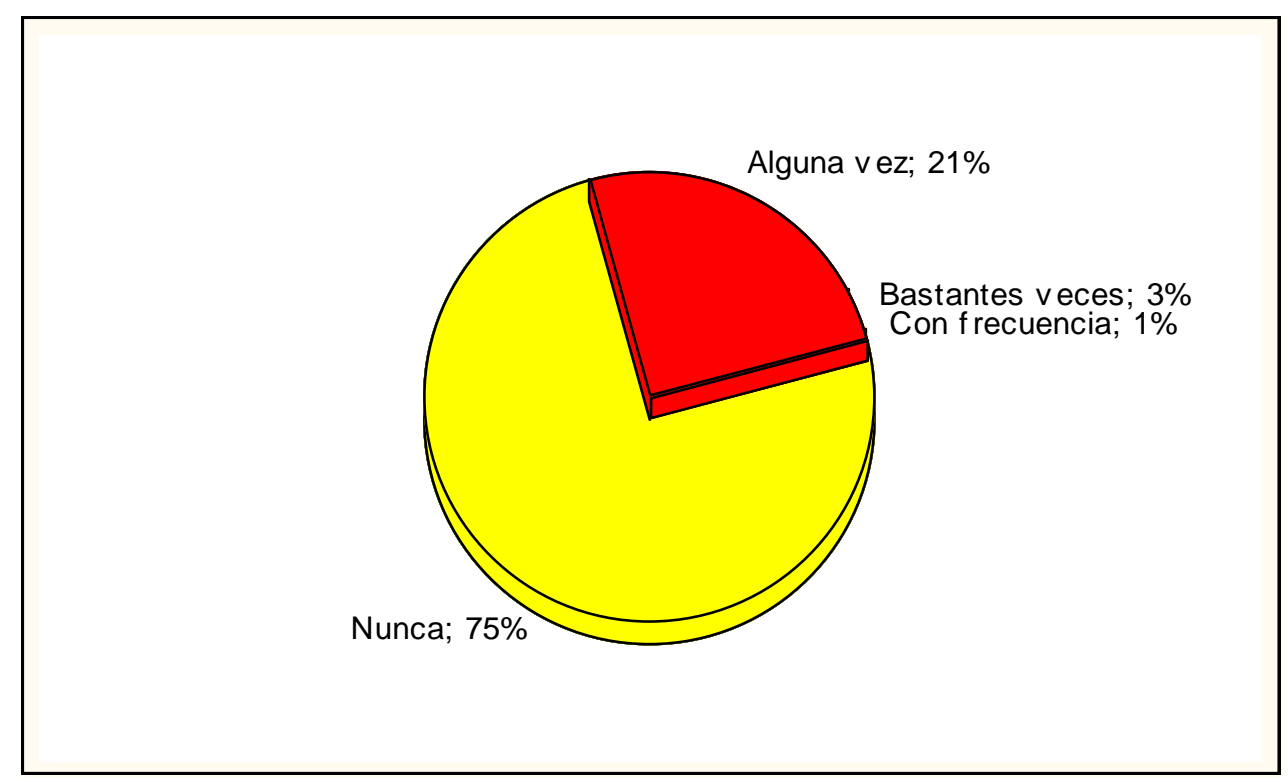

Figura 1. Frecuencia con la que juegan al rol los encuestados

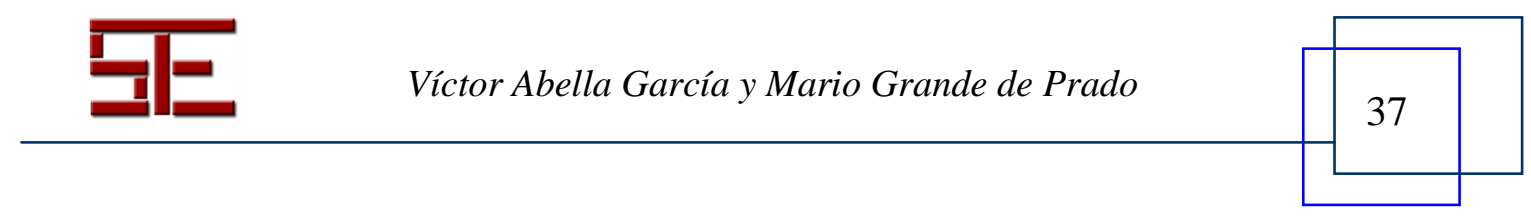




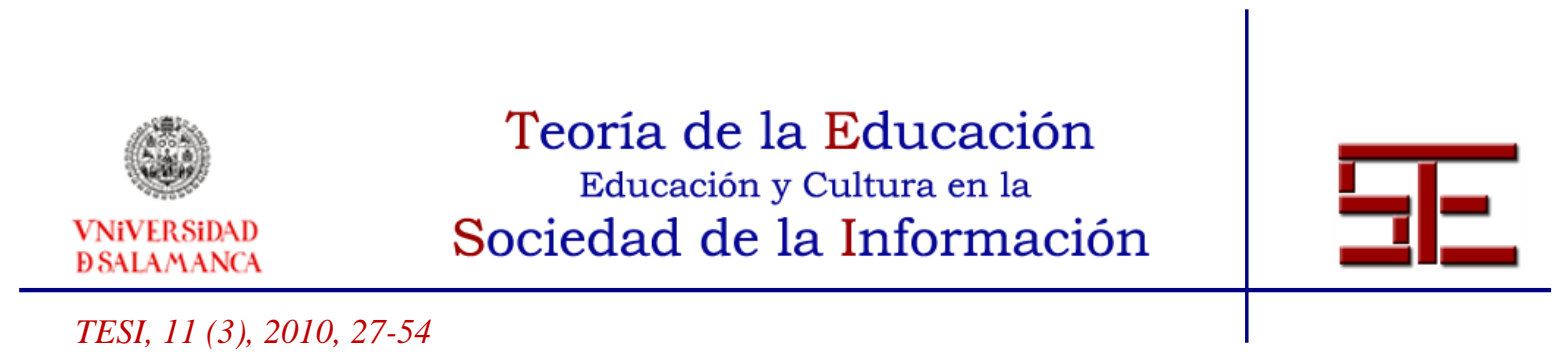

\subsection{Opinión General sobre los juegos de rol}

Sobre la opinión de los juegos de rol la mayoría de los encuestados (53\%) se consideran indiferentes ante los juegos de rol. Siguiendo en orden de frecuencias, el 23\% tienen una opinión mala sobre los juegos de rol, mientras que el $24 \%$ restante poseen una opinión buena o muy buena de los juegos de rol (Figura 2).

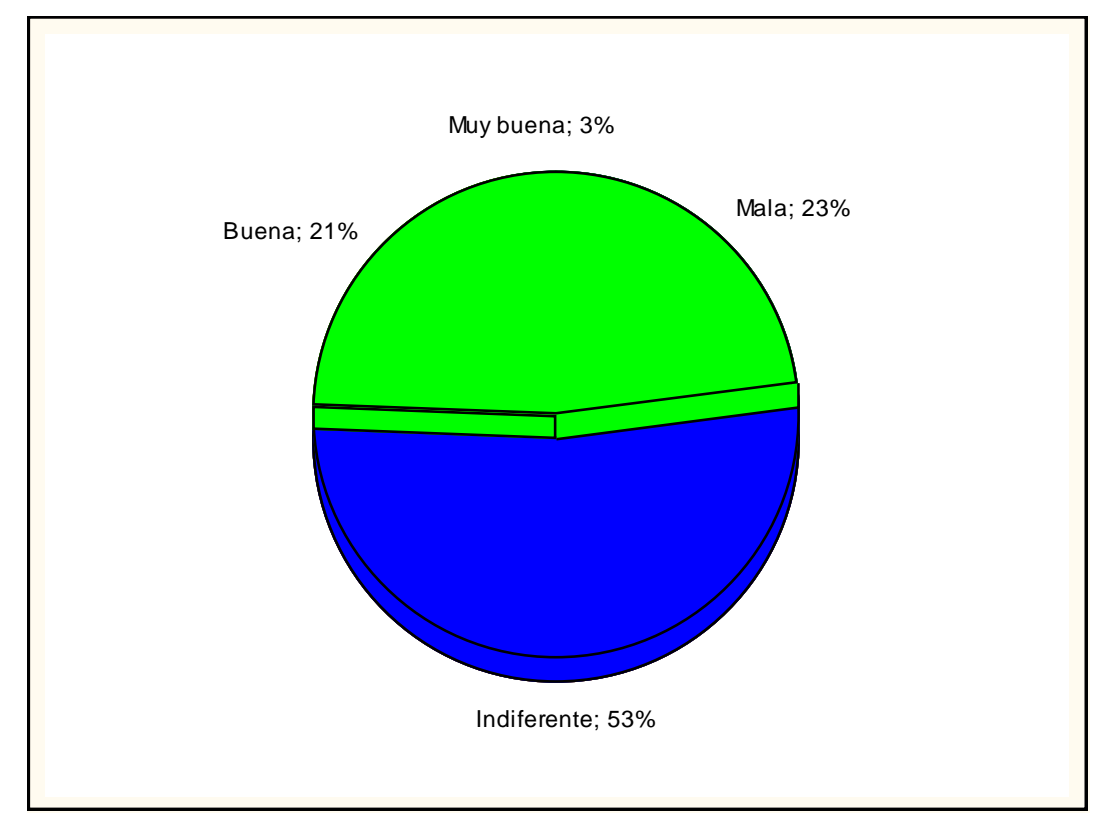

Figura 2. Valoración de los juegos de rol

Los análisis han mostrado que existen diferencias significativas en la opinión general que manifiestan los estudiantes de la ESO si se comparan sus respuestas con las dadas por los estudiantes universitarios $(\mathrm{U}=1,304 ; \mathrm{Z}=-2,70 ; \mathrm{p}=<, 05)$. Tal y como se puede ver en la Figura 3, la opinión general sobre los juegos de rol de los estudiantes de secundaria es mejor que la manifestada por los estudiantes universitarios. De éstos, un $28 \%$ tienen una opinión mala de los juegos de rol, mientras que un $19 \%$ poseen una opinión buena (18\%) o muy buena $(1 \%)$. Contrariamente en el caso de los estudiantes de ESO es un $36 \%$ los que tienen una buena opinión de los juegos de rol y un $10 \%$ son los que manifiestan una opinión mala. Por otro lado, en ambos grupos la opinión mayoritaria es la indiferencia, un 52\% para los estudiantes universitarios y un 54\% para los estudiantes de secundaria.

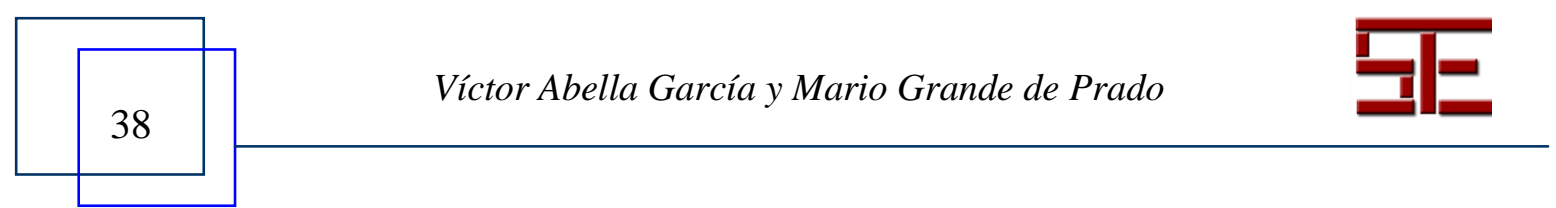



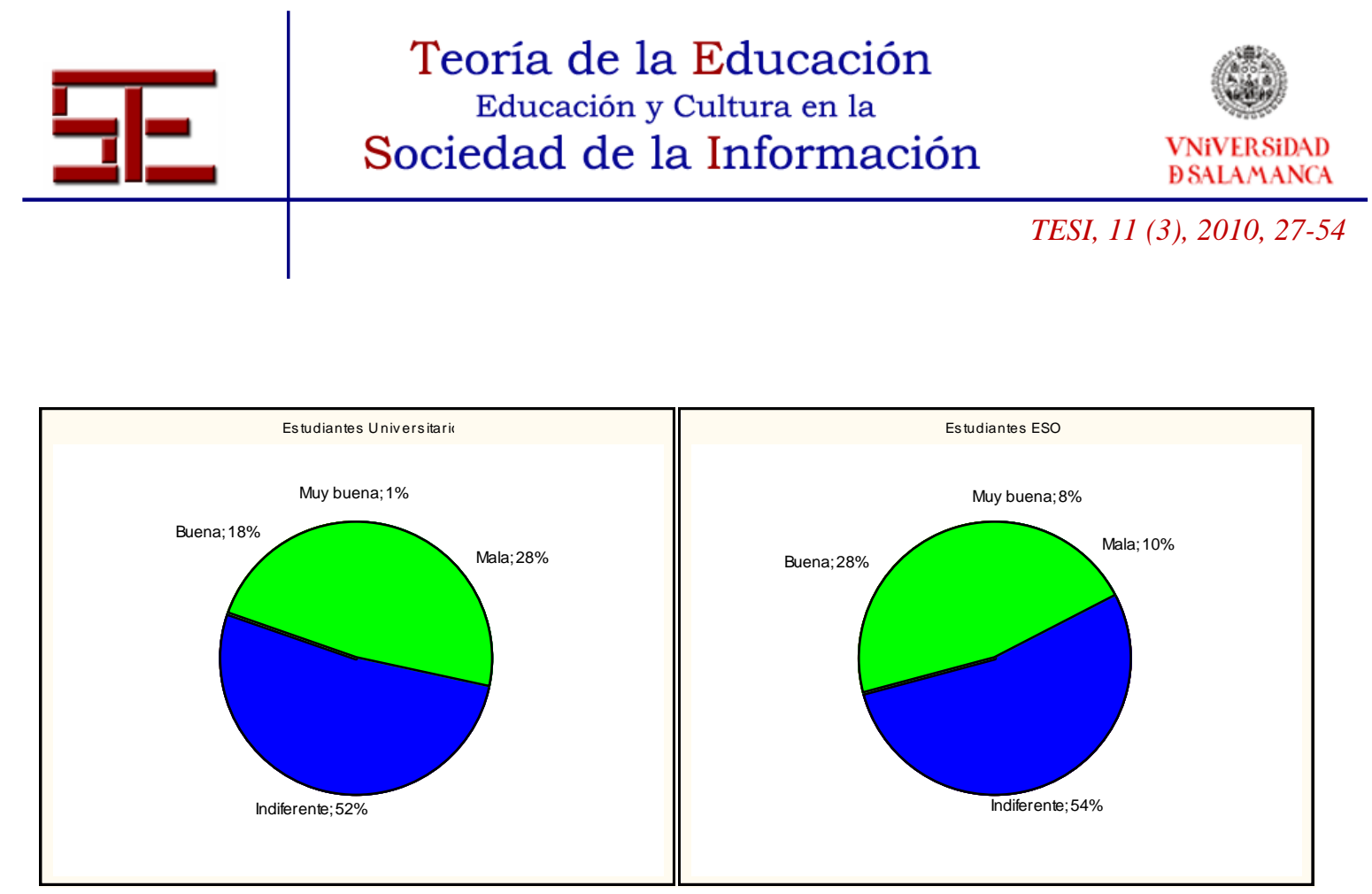

Figura 3. Percepción general sobre los juegos de rol en estudiantes universitarios y en estudiantes de la ESO.

Se han comparado las respuestas de los sujetos que manifiestan jugar al rol (24\%) y los que han respondido que no lo hacen (76\%). Ambos grupos difieren de forma estadísticamente significativa en la opinión que tienen sobre los juegos de rol $(\mathrm{U}=786$; $\mathrm{Z}=4,62 ; \mathrm{p}<, 001)$, siendo el grupo que sí ha jugado el grupo que los valora de una forma más positiva.

\subsection{Peligrosidad de los juegos}

En lo que respecta a la peligrosidad de los juegos de rol (ver Figura 4) la mayoría (76\%) consideran que su peligrosidad es baja o inexistente. Del grupo restante un $21 \%$ opina que los juegos de rol pueden ser un poco peligrosos. Finalmente es tan sólo un $3 \%$ de la muestra total los que creen que los juegos de rol son muy peligrosos.

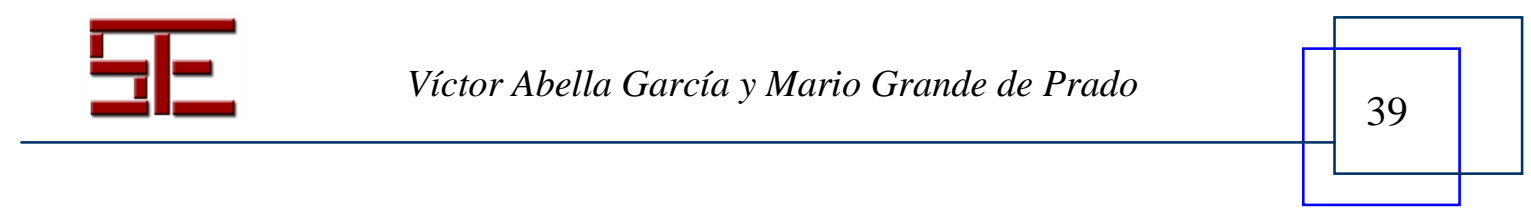





Figura 4. Percepción de la peligrosidad de los juegos de rol.

Hemos comparado las respuestas de varones y mujeres en lo que respecta a la peligrosidad de los juegos de rol. Para ver si las diferencias en las respuestas son significativas hemos utilizado la prueba $U$ de Mann-Whitney, debido a que la peligrosidad de los juegos se ha evaluado mediante una escala ordinal.

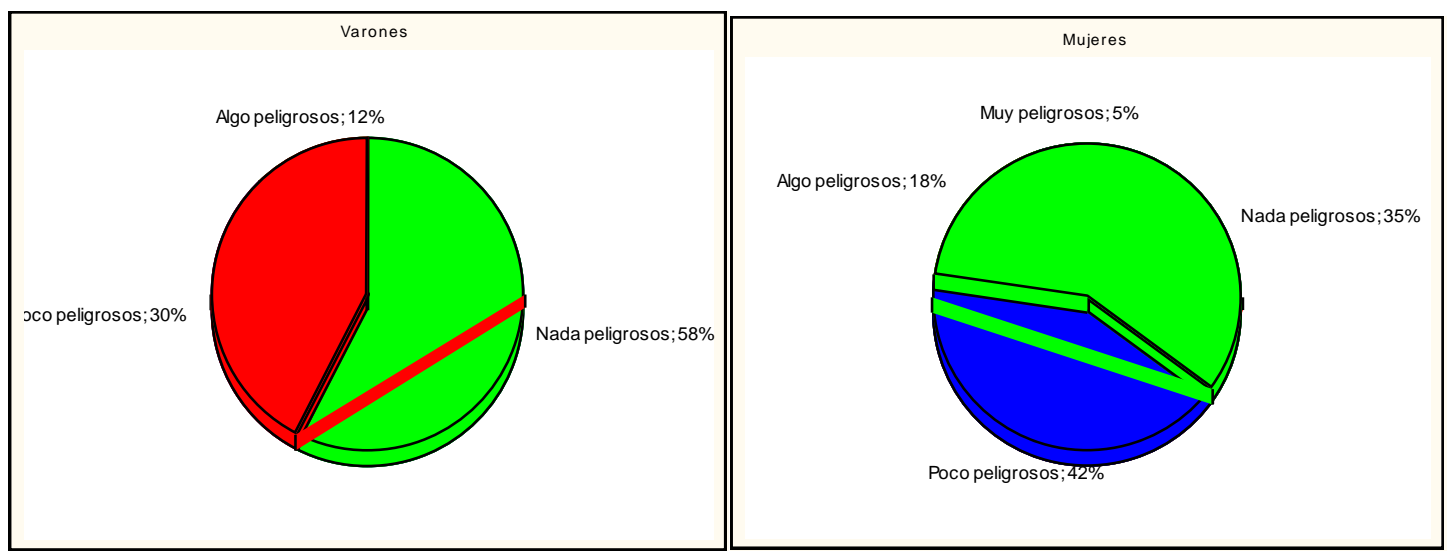

Figura 5. Comparación entre mujeres y varones sobre la peligrosidad de los juegos de rol.

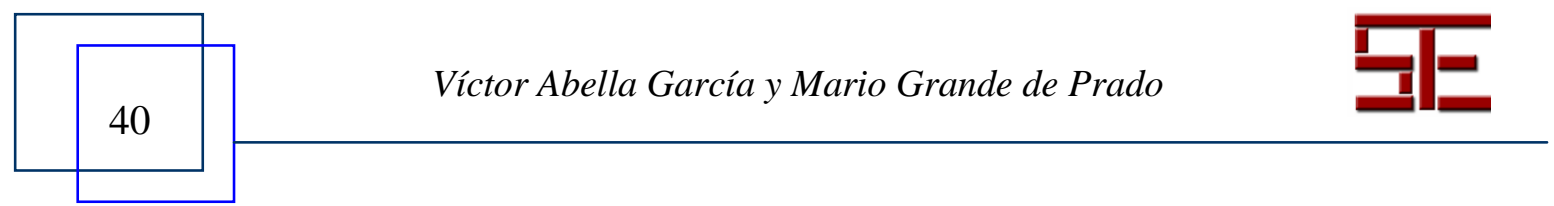




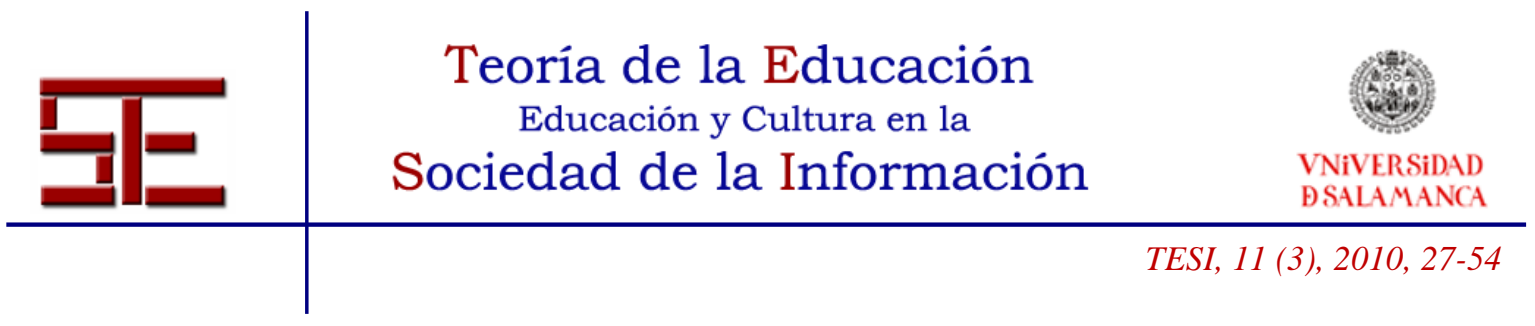

Al comparar las respuestas de hombres y mujeres (Figura 5) vemos que los varones no consideran en ningún momento que los juegos de rol sean muy peligrosos, mientras que el 5\% de las mujeres sí consideran que son muy peligrosos. Los varones consideran mayoritariamente $(58 \%)$ que los juegos de rol no son nada peligrosos, mientras que para las mujeres este valor alcanza el 35\%. La prueba U de Mann-Whitney ha mostrado que existen diferencias significativas entre varones y mujerescuanto a la percepción de peligrosidad de los juegos de rol $(\mathrm{U}=1,202 ; \mathrm{Z}=-2,131 ; \mathrm{p}<, 05)$, que indica que los varones perciben los juegos de rol como menos peligrosos que las mujeres.

También hemos obtenido diferencias en cuanto a la percepción de la peligrosidad de los juegos de rol al comparar las respuestas de los estudiantes universitarios y los de secundaria $(\mathrm{U}=1,389 ; \mathrm{Z}=2,06 ; \mathrm{p}<, 05)$. Los estudiantes universitarios consideran, de una forma significativa, los juegos de rol más peligrosos que lo que los consideran los estudiantes de ESO (Figura 6). Entre los universitarios un $76 \%$ los consideran poco peligrosos $(41 \%)$ o nada peligrosos $(35 \%)$, mientras que entre los estudiantes de secundaria el porcentaje de los que los consideran poco peligrosos es de un $37 \%$, mientras que el porcentaje de los que los ven como nada peligrosos alcanza el $53 \%$. Con respecto a la peligrosidad entre los estudiantes universitarios el $23 \%$ de los sujetos opinan que los juegos de rol son algo o muy peligrosos, mientras que esta opinión entre los encuestados de secundaria desciende al $11 \%$.

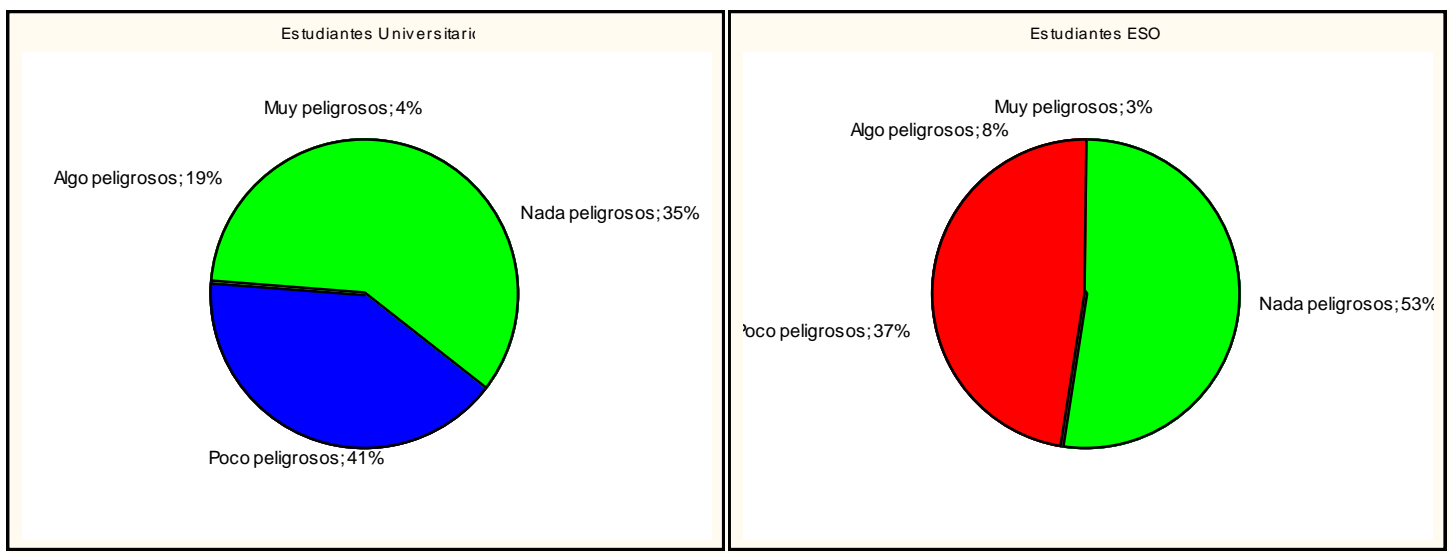

Figura 6. Percepción de la peligrosidad de los juegos de rol en universitarios y estudiantes de secundaria.

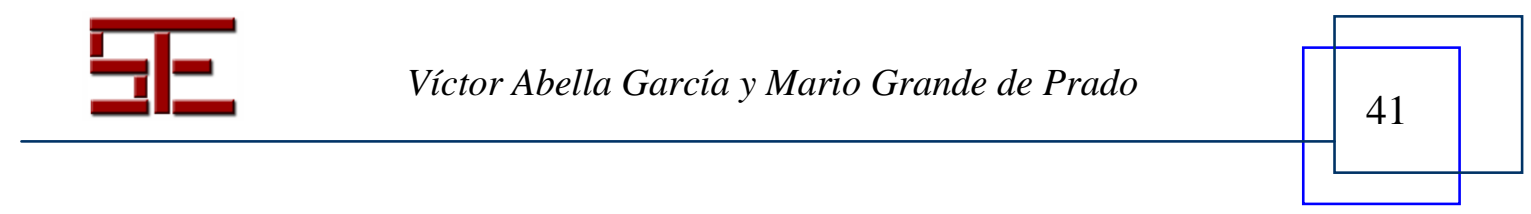




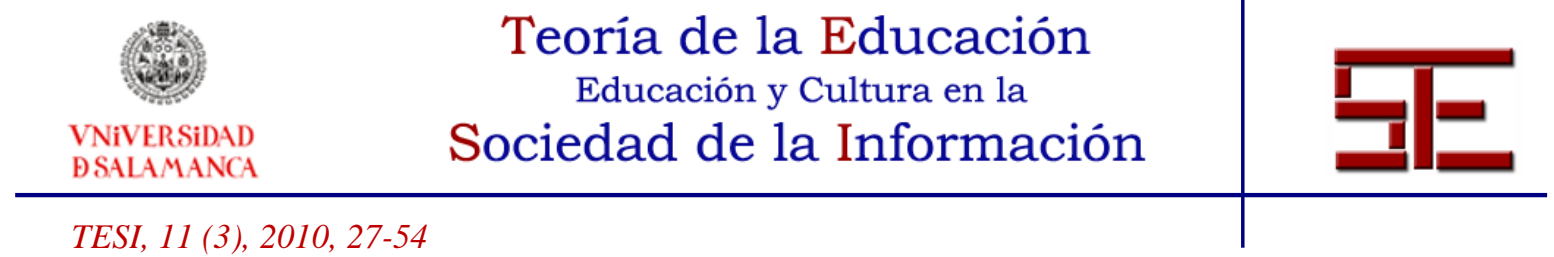

De la misma manera contrastando las opiniones de los sujeto que juegan al rol y de los que no (Figura 7), también aparecen diferencias significativas con respecto a la peligrosidad de los juegos a favor de los que no han jugado. Es decir, que de forma general los sujetos que no han jugado a rol consideran estos juegos más peligrosos que aquellos que han jugado $(\mathrm{U}=1185,5 ; \mathrm{Z}=2,39 ; \mathrm{p}<, 05)$. Así la percepción de peligro entre los que sí han jugado a rol oscila entre un $3 \%$ que los consideran muy peligrosos y un $6 \%$ que los consideran como algo peligrosos. Las mismas opiniones dentro del grupo de los que no han jugado alcanzan un $4 \%$ para quienes los consideran muy peligrosos y un $19 \%$ para los que creen que son algo peligrosos.

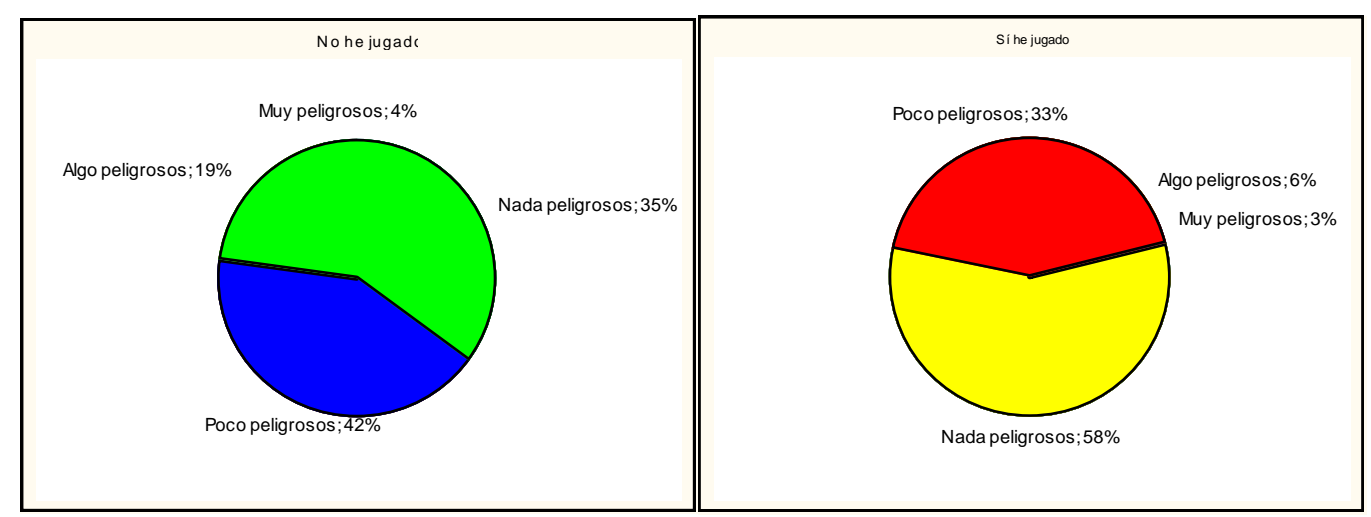

Figura 7. Percepción de la peligrosidad de los juegos de rol entre los sujetos que han jugado y los que no han jugado a rol.

\subsection{Intención de probar los juegos de rol}

Se preguntó a los encuestados si se animarían a probar los juegos de rol. Un $68 \%$ emitieron una respuesta afirmativa, mientras que el resto, tal y como se puede ver en la Figura 8 , no se animarían a probar los juegos de rol.

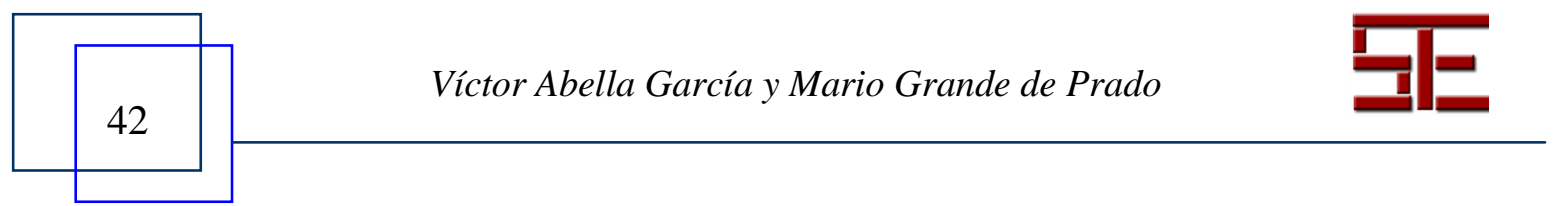



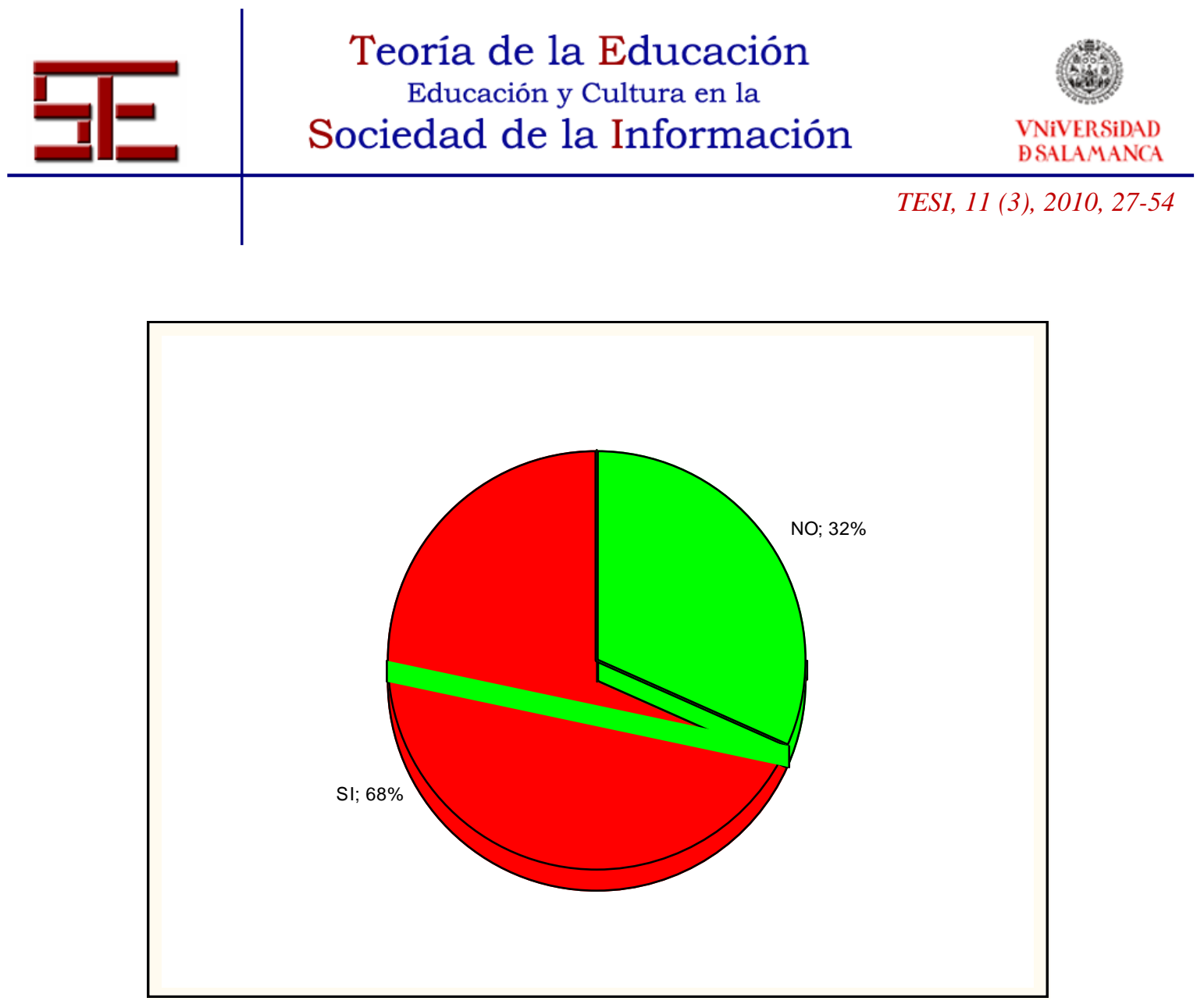

Figura 8. Intención de probar a jugar a un juego de rol.

\subsection{Edad de comienzo}

A los encuestados se les propusieron cuatro edades (10, 12, 18 y 21 años) para que escogieran la que ellos consideraran como más adecuada para comenzar a iniciarse en los juegos de rol (Figura 9). La opinión mayoritaria (47\%) es que la edad más adecuada para comenzar a jugar a juegos de rol es a los 18 años. Contrariamente, la opinión minoritaria es la que considera que la edad más adecuada son los 21 años (6\%).

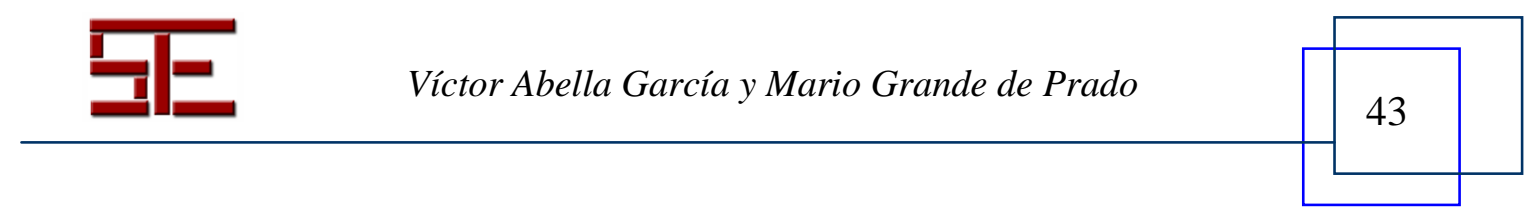



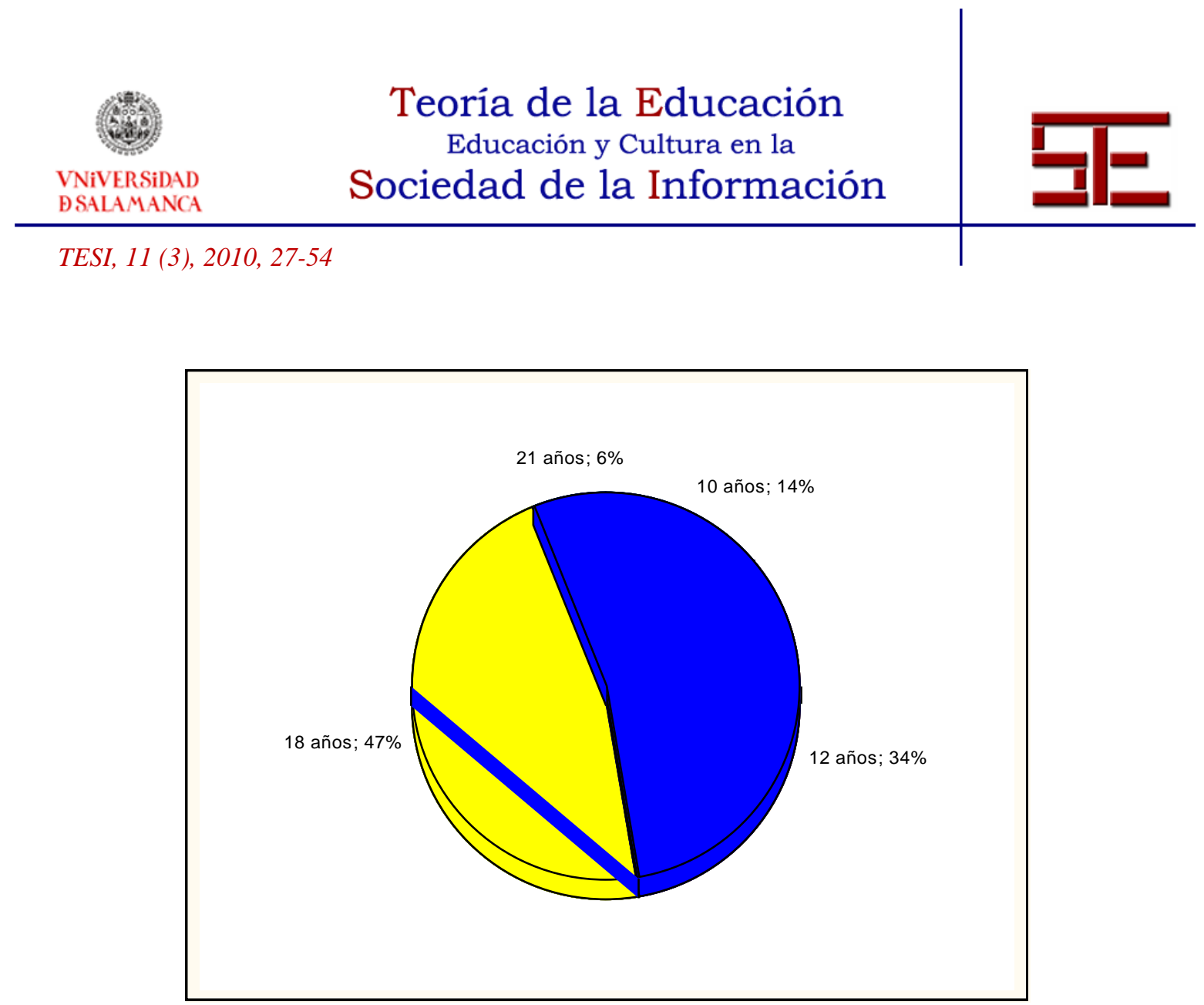

Figura 9. Opinión sobre la edad a la que debería comenzarse a jugar a rol.

Hemos obtenido diferencias de género $(U=1223 ; \mathrm{Z}=-2,336 ; \mathrm{p}<, 05)$ en lo que respecta a la edad a la que consideran adecuado que se puedan comenzar a jugar a rol. Estas diferencias indican que, de forma significativa, los varones consideran que la edad a la que creen que se puede jugar a rol es más baja en comparación con la consideración que hacen las mujeres. Por otro lado, tal y como se puede comprobar en la Figura 10, también hemos encontrado diferencias entre los estudiantes universitarios y los de secundaria $(U=1245,5 ; Z=2,85 ; p<, 01)$ en la edad en la que los encuestados creen que se debería poder empezara a jugar a rol.

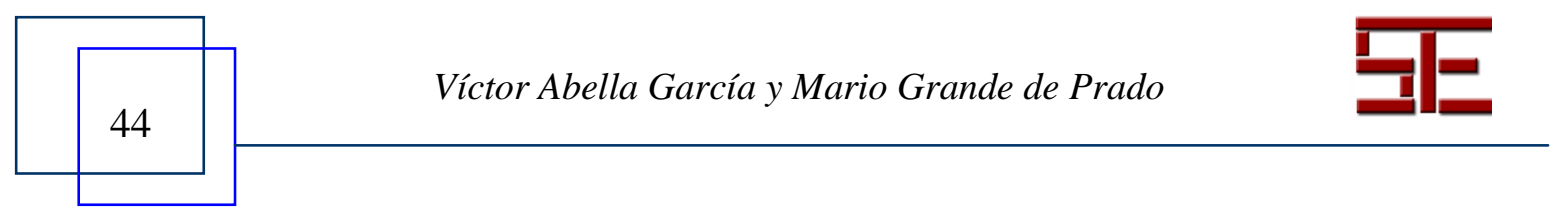



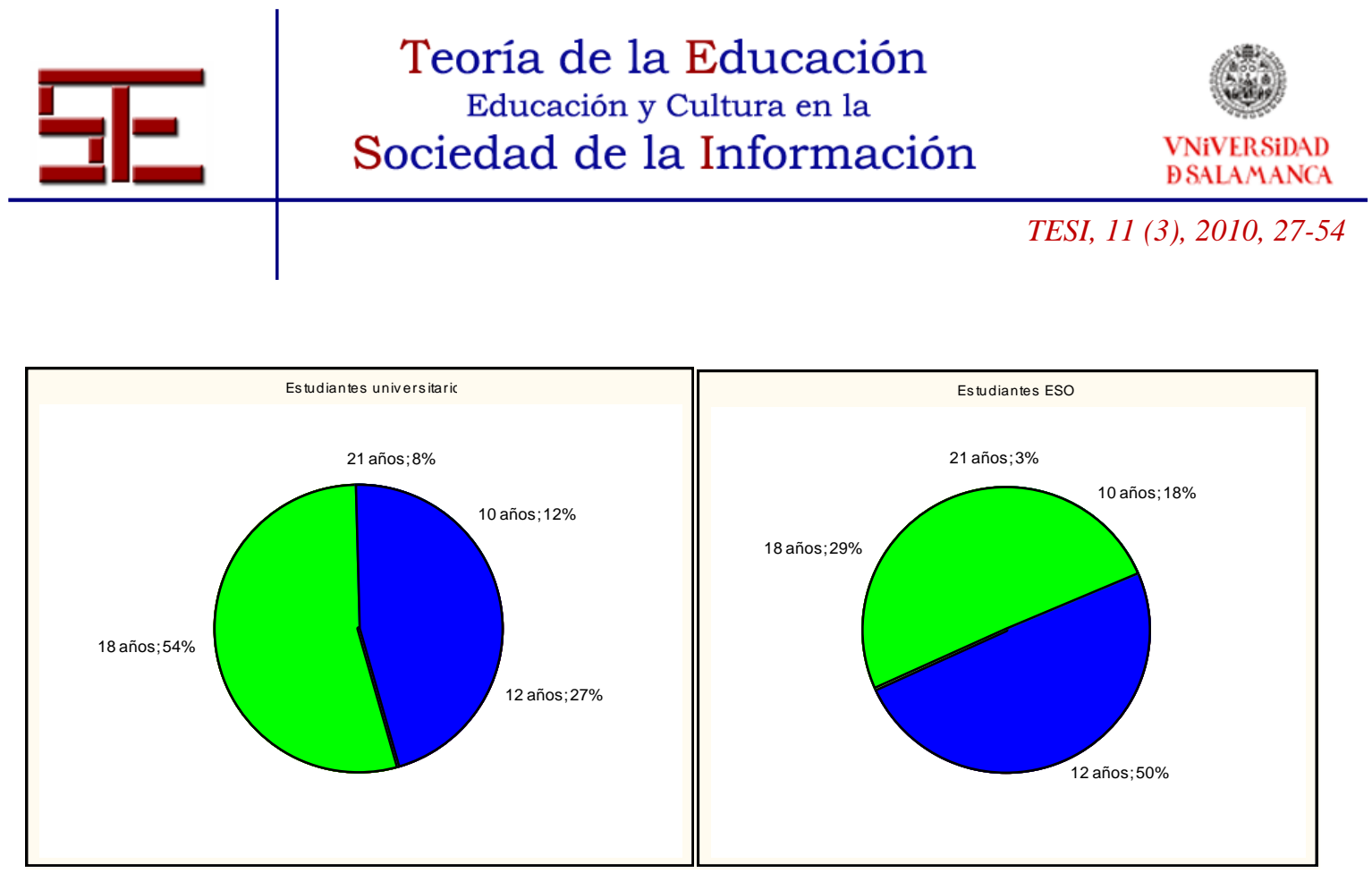

Figura 10. Edad a la que universitarios y estudiantes de ESO creen que se puede empezar a jugar a rol.

Los análisis mediante la $\mathrm{U}$ de Mann-Whitney incluyendo como variable independiente el haber jugado o no a rol han mostrado diferencias significativas $(U=950 ; Z=-3,60$; $\mathrm{p}<, 001)$ entre estos dos grupos respecto a la edad en la que creen que es adecuado el comenzar a jugar a rol (Figura 11). Los que han jugado a rol consideran que los sujetos pueden comenzar a jugar antes a rol. Un $69 \%$ de los que han jugado consideran que no hace falta ser mayor de edad para comenzar a jugar a rol, mientras que en el caso de los no jugadores esta opinión la comparten sólo el $41 \%$ de los sujetos.

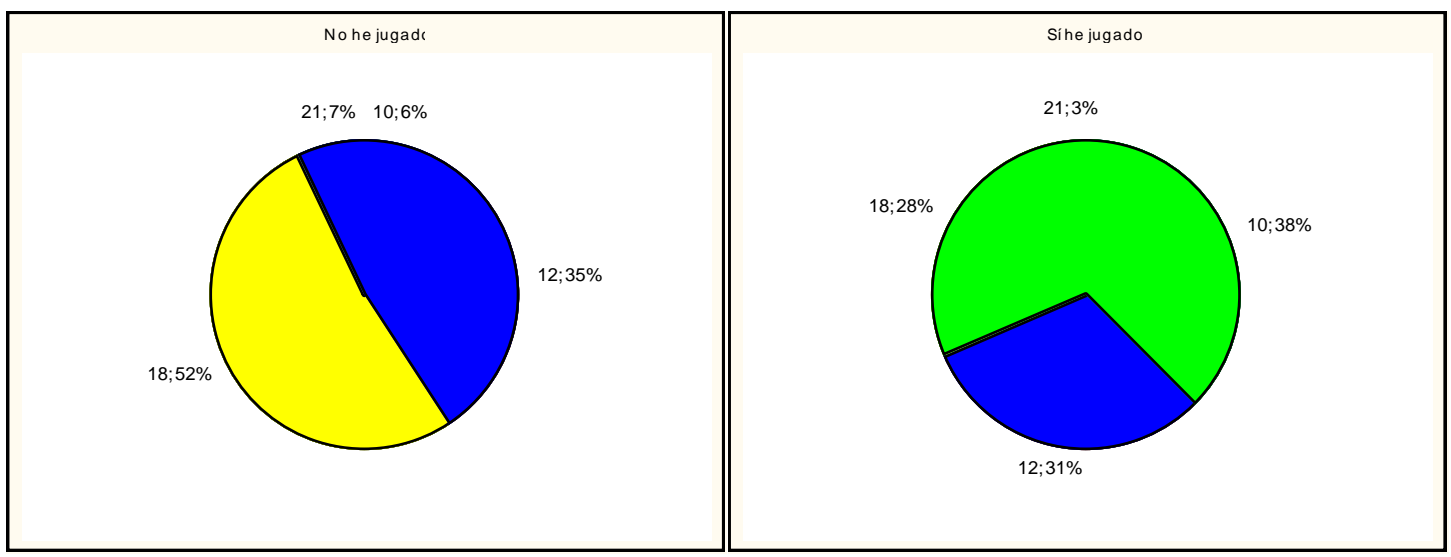

Figura 11. Edad a la que se puede comenzar a jugar a rol en función de si se ha jugado o no a rol.

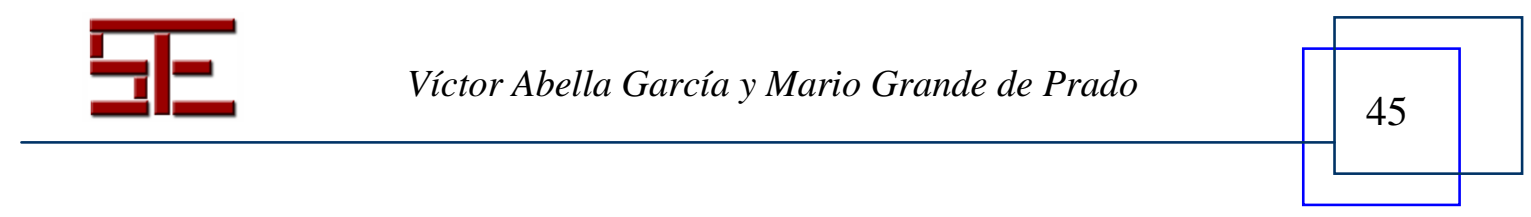




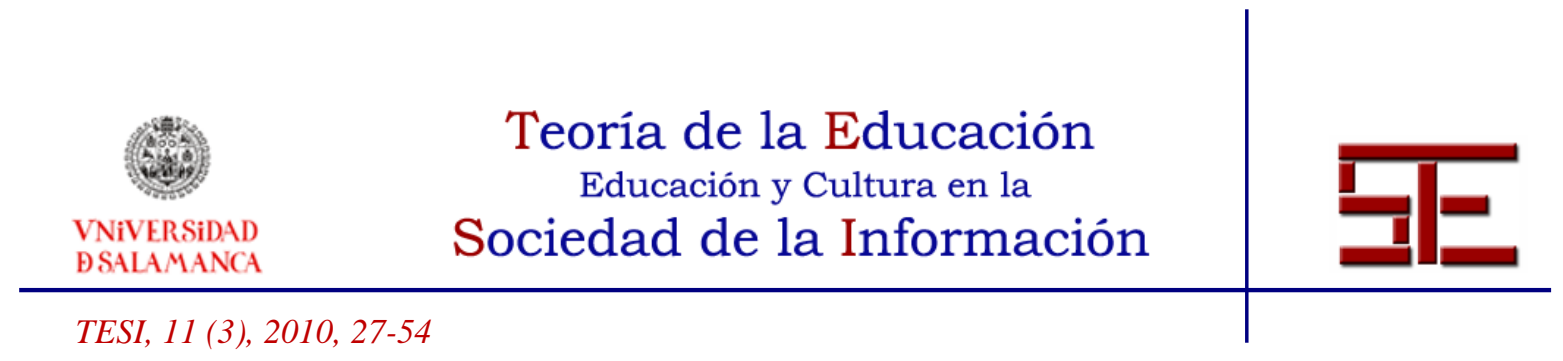

\subsection{Estereotipos}

Respecto a los estereotipos que se suelen asignar a los jugadores de rol un $47 \%$ considera que son ciertos la mayoría de las veces. Un $16 \%$ considera que esos estereotipos responden a la realidad, mientras que la opinión contraria, es decir, que los estereotipos no son ciertos, es compartida por un $37 \%$ de los encuestados.

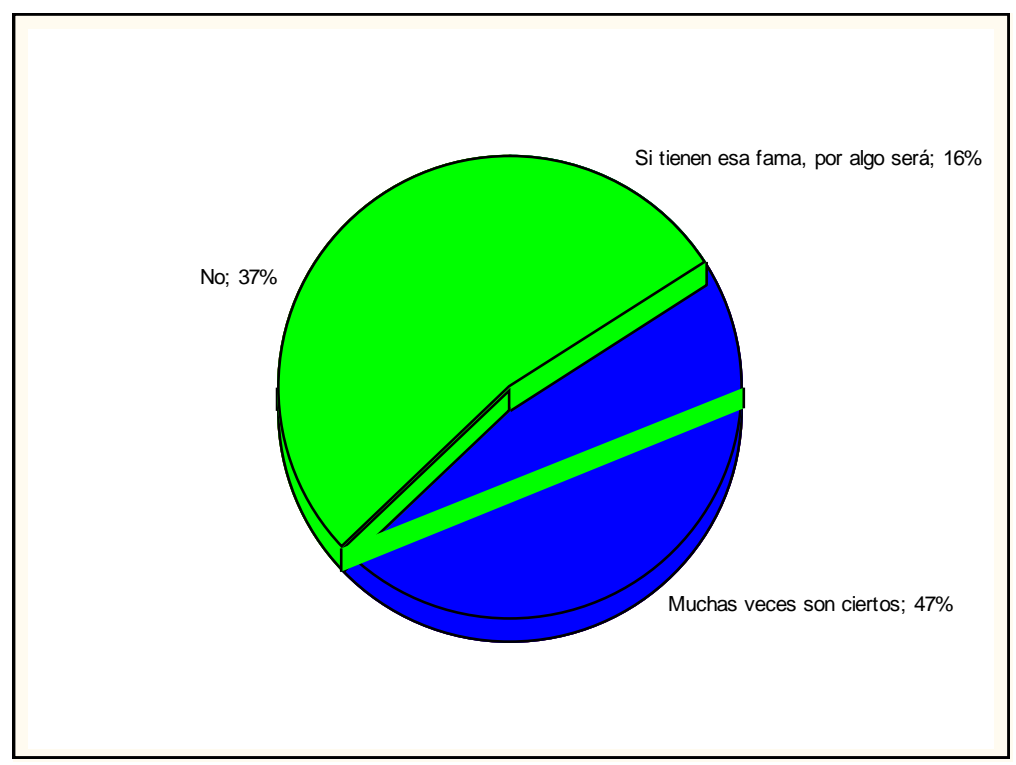

Figura 12. Percepción de los estereotipos de los jugadores de rol.

\subsection{Imagen en los medios de comunicación}

La opinión mayoritaria $(80 \%)$ de los encuestados con respecto a si los medios de comunicación muestran una imagen real de los juegos de rol es que a veces esta imagen sí se corresponde con la realidad. Son sólo el $4 \%$ de los sujetos los que consideran que la imagen que ofrecen los medios es la que se corresponde con la realidad.

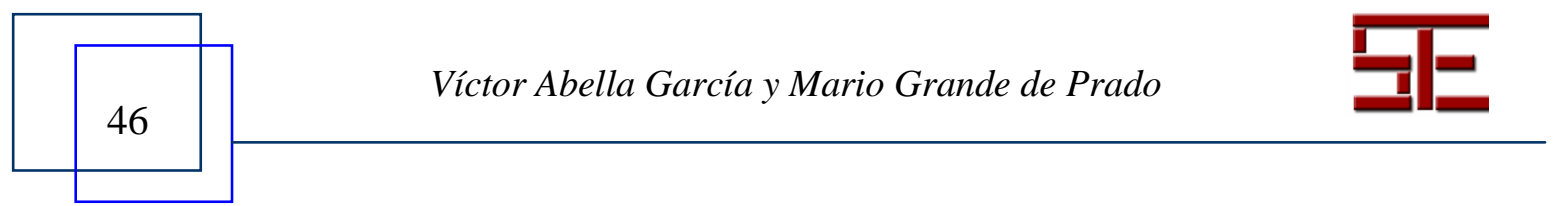



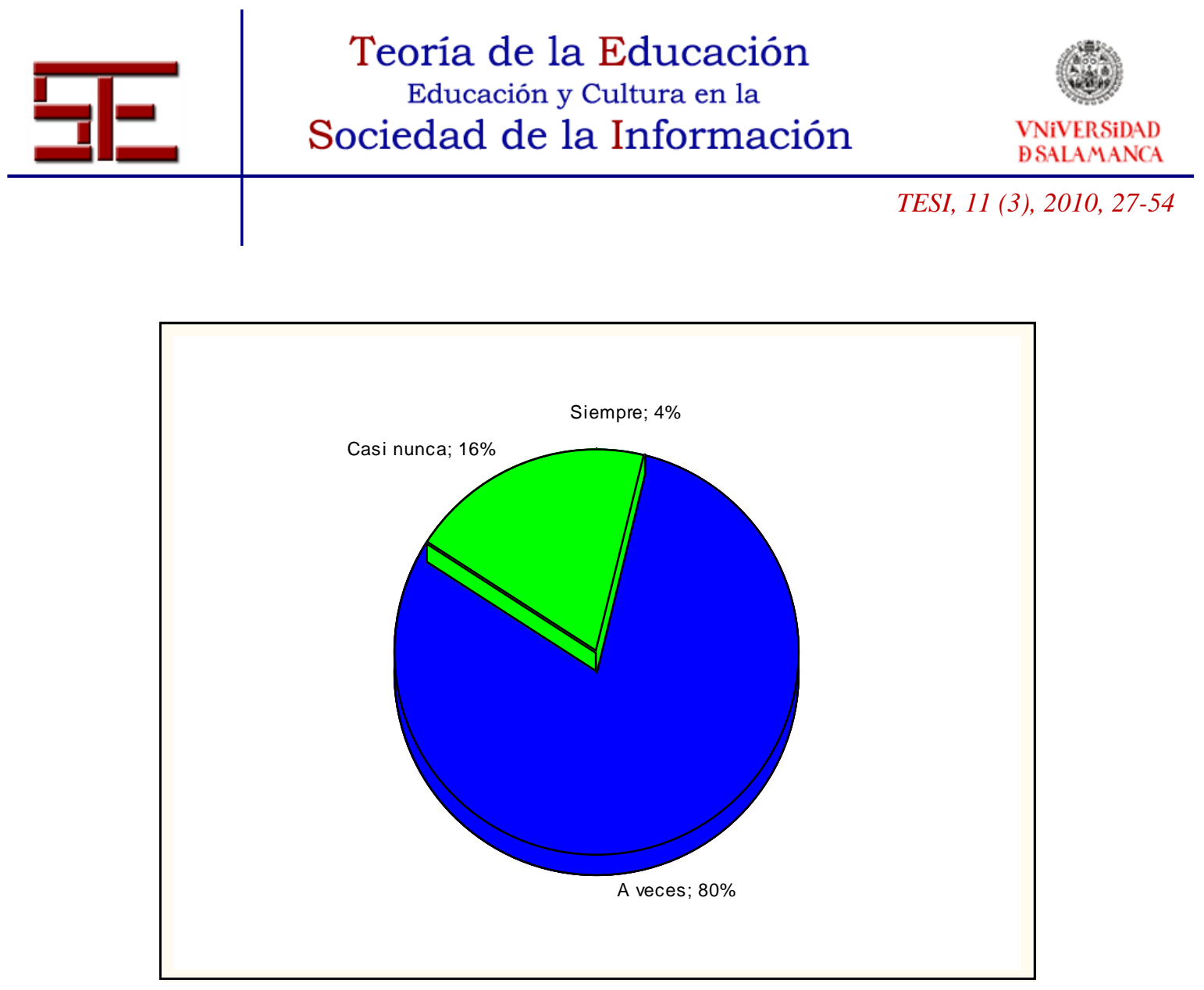

Figura 13. Opinión sobre la imagen que dan los medios de comunicación de los juegos de rol.

Al hacer el análisis por grupos en función del sexo la opinión mayoritaria entre varones y mujeres sigue siendo que tan sólo algunas veces los medios de comunicación ofrecen una imagen realista de los juegos de rol (Figura 13). Hemos obtenido una asociación significativa entre el sexo del sujeto y la percepción que tienen sobre cómo presentan los medios a los juegos de rol $\left(\mathrm{X}_{(2)}^{2}=10,08 ; \mathrm{p}<, 01\right)$. Esta asociación indica que los varones, en un $32 \%$, creen que los medios de comunicación casi nunca son fieles a la realidad a la hora de hablar sobre los juegos de rol, mientras que en las mujeres esta opinión representa el 10\% del total. También hemos encontrado asociación significativa entre esta misma variable y la pertenencia al grupo universitario o de estudiantes de secundaria $\left(\mathrm{X}_{(2)}^{2}=6.80 ; \mathrm{p}<, 05\right)$. Esta asociación indica que el $86 \%$ del grupo de estudiantes universitarios considera que la imagen que dan los medios de los juegos de rol sólo se ajusta a veces a la realidad, en cambio esta creencia es compartida por el $67 \%$ de los estudiantes de secundaria. El $26 \%$ de estos últimos creen que la imagen dada casi nunca se ajusta a la realidad, siendo este porcentaje significativamente menor $(12 \%)$ en el grupo de estudiantes universitarios.

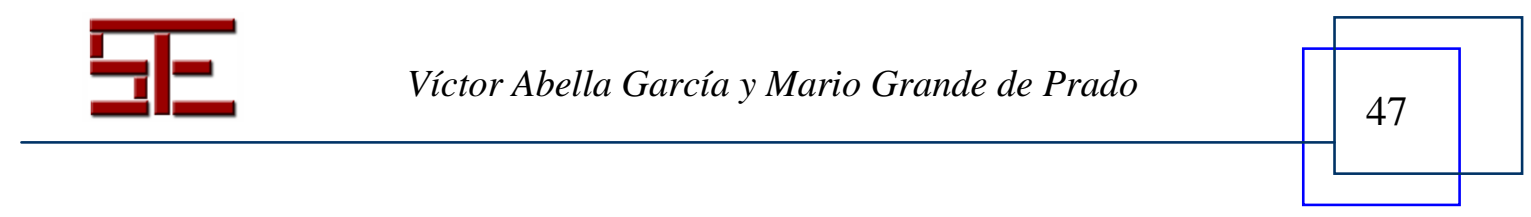



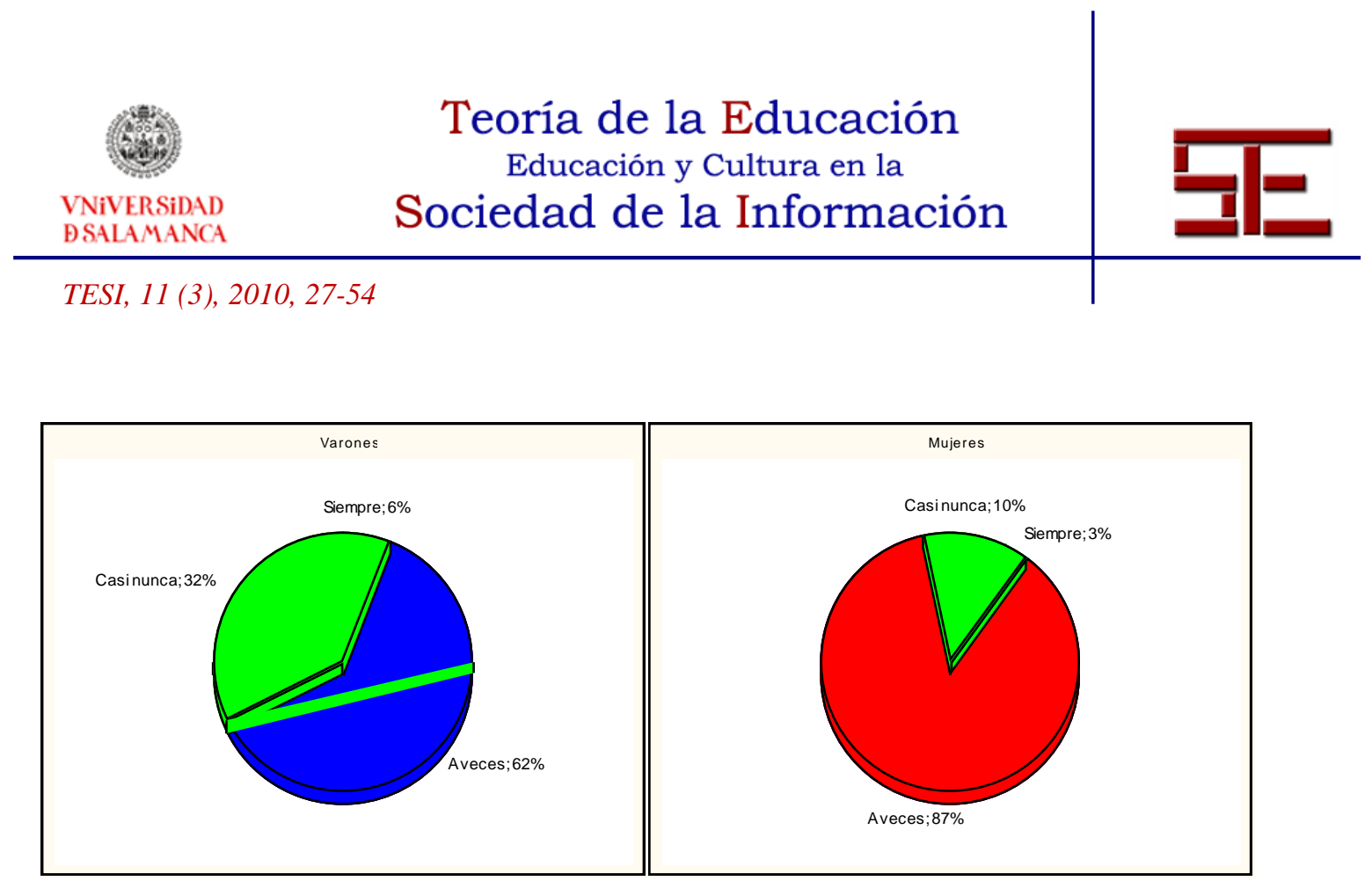

Figura 14. Opinión de varones y mujeres sobre el ajuste a la realidad de las noticias que los medios de comunicación presentan sobre el rol.

\subsection{Aplicabilidad educativa}

Se preguntó a los encuestados sobre las posibilidades que tendrían los juegos de rol de ser aplicados en educación. Tal y como se muestra en la Figura 14, la mayoría (61\%) considera que los juegos de rol tienen poca o ninguna utilidad en educación. Del porcentaje restante, un $8 \%$ considera que los juegos de rol son totalmente aplicables en educación.
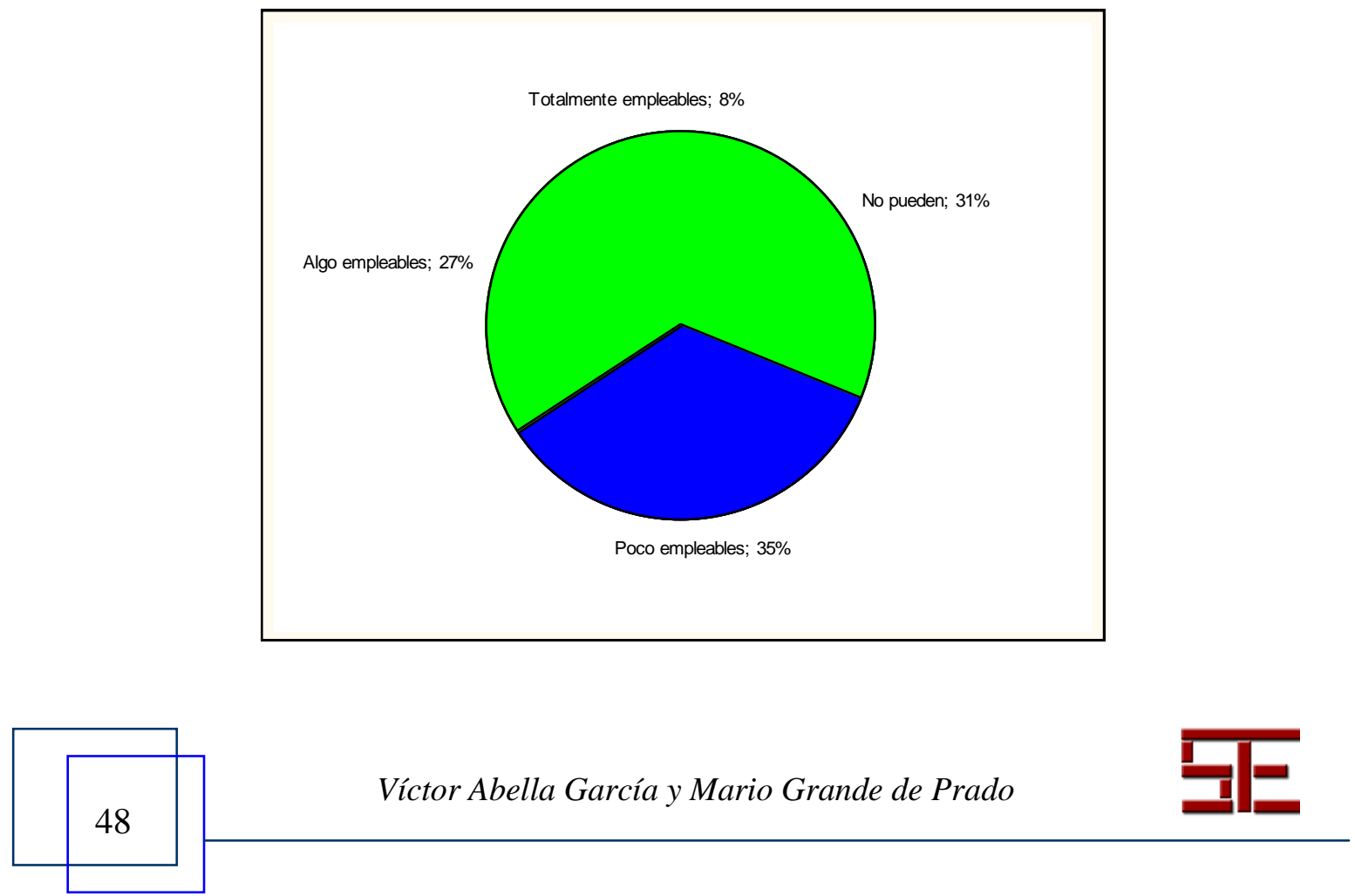


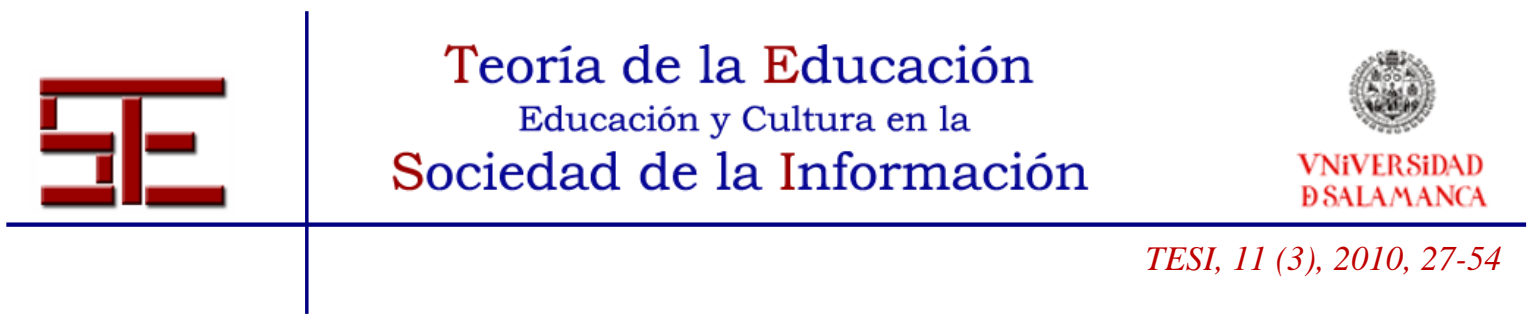

Figura 15. Respuestas a la pregunta: ¿Crees que los juegos de rol pueden ser empleados en educación?

Si comparamos las respuestas dadas por los sujetos que han jugado al rol con las que dan los sujetos que no lo han hecho, los análisis muestran que difieren significativamente en la posibilidad que ven a dichos juegos para aplicarse en educación $(\mathrm{U}=1119 ; \mathrm{Z}=2,77 ; \mathrm{p}<, 01)$. De esta manera, aquellos que han jugado al rol creen que los juegos de rol son más útiles en educación en comparación con lo que opinan los que no han jugado (Figura 16). De los que han jugado, el 64\% de los encuestados creen que los juegos de rol sí se pueden aplicar en educación, mientras que ese porcentaje desciende hasta el $26 \%$ entre los sujetos que han manifestado no jugar al rol.

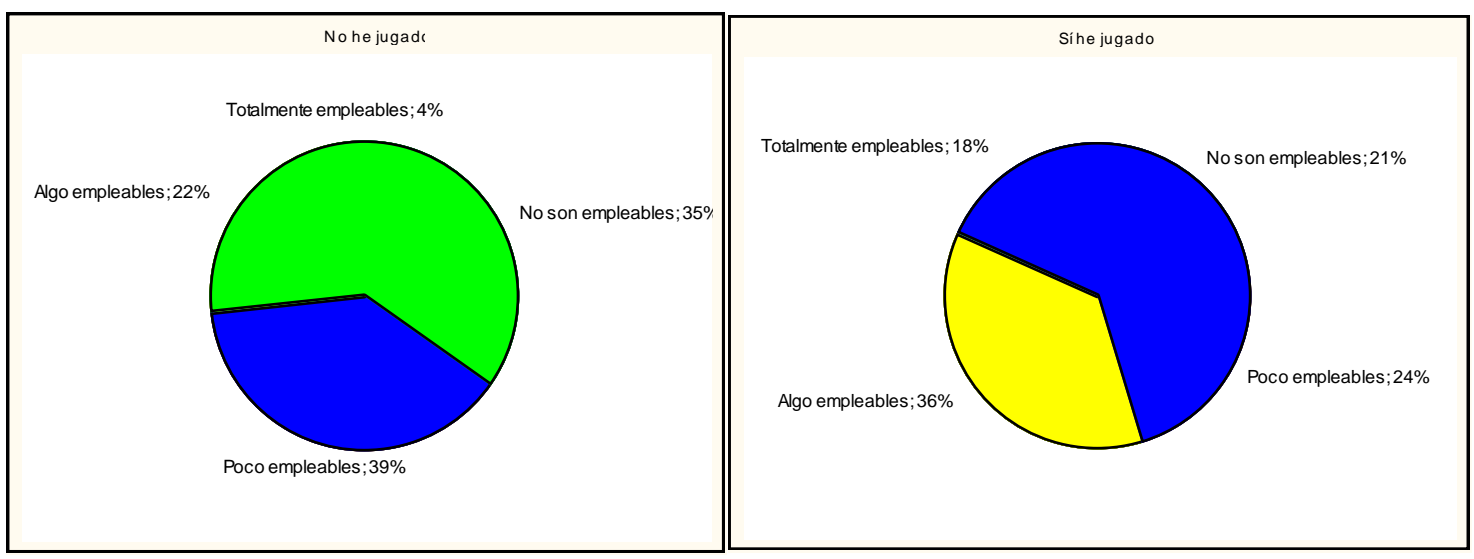

Figura 16. Opinión sobre la utilidad de los juegos de rol en educación para los que han jugado a rol y los que no.

\section{4.- DISCUSIÓN}

Con este estudio hemos intentado conocer la percepción de un grupo de estudiantes, tanto de secundaria como universitarios, sobre diferentes aspectos de los juegos de rol. En el caso de los universitarios, el hecho de que sean alumnos de Magisterio resulta especialmente relevante para conocer la predisposición de los futuros docentes en relación a una herramienta que aporta numerosas ventajas a nivel didáctico, como, por ejemplo, trabajar actitudes, trabajo en equipo, fomentar la lectura...

Los resultados han mostrado que el $75 \%$ de los encuestados nunca han jugado a rol.

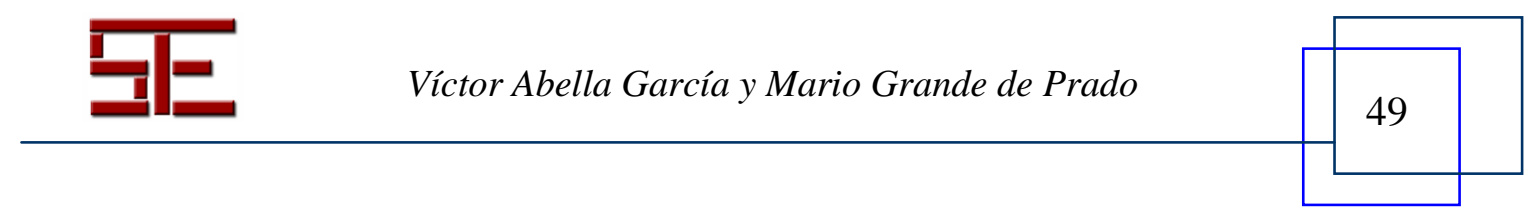




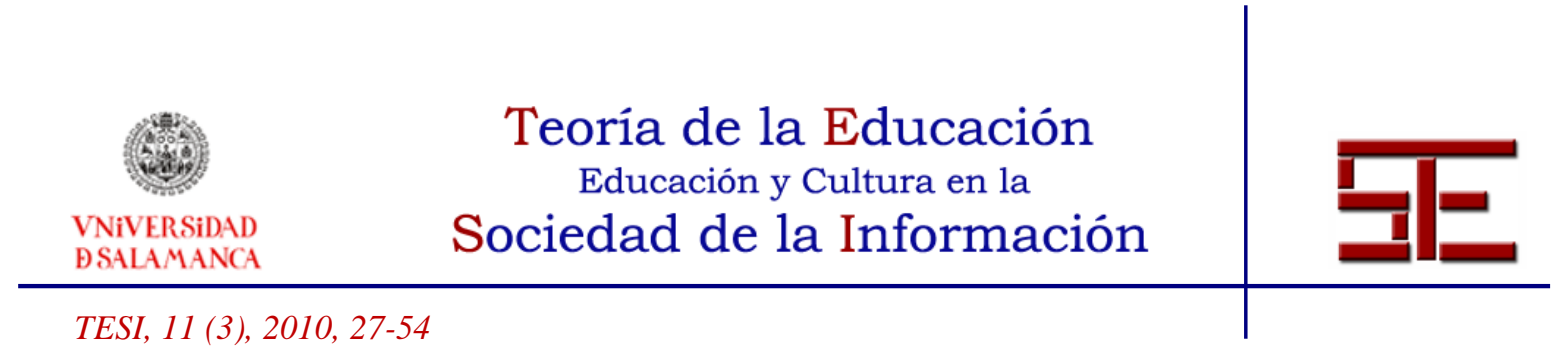

Determinadas organizaciones sociales han considerado a los juegos de rol como causantes de conductas desadaptativas, por eso se incluyó una pregunta en la que se pedía una opinión general sobre los juegos de rol. Dentro de la opinión general la mayoría de los encuestados muestran una relativa indiferencia hacia los juegos de rol. El porcentaje de sujetos que muestran opiniones opuestas, es decir, los que tienen una opinión positiva frente a los que tienen una opinión negativa, es casi idéntica $(24 \%$ positiva y $23 \%$ negativa).Con respecto a la opinión general sobre los juegos de rol parece que la edad del sujeto juega un papel importante, puesto que nuestros análisis han mostrado como los estudiantes de secundaria tienen una opinión sobre los juegos de rol que es significativamente mejor que la que poseen los estudiantes universitarios, tal vez debido a que el impacto mediático negativo en relación a los juegos de rol ha ido remitiendo con el tiempo.

En múltiples ocasiones se ha señalado a los juegos de rol como peligrosos, ya que se les ha descrito como causa de conductas antisociales o incluso que conllevan la normalización de la violencia (Ascherman, 1993). En este sentido nuestros análisis indican que la inmensa mayoría de los encuestados (el 76\%) consideran que los juegos de rol son poco o nada peligrosos. Estos resultados serían acordes con los obtenidos en otras investigaciones sobre personalidad y juegos de rol, como, por ejemplo, la realizada por Abyeta y Forest (1991), quienes no encontraron ninguna relación entre las conductas delictivas autoinformadas y el jugar a rol, o las realizadas por Simón (1987; 1998) sobre el perfil de aficionados a los juegos de rol.

Respecto a la peligrosidad percibida, el género influye en dicha percepción, ya que según nuestros análisis las mujeres perciben los juegos de rol como peligrosos en mayor medida que los varones. A este respecto, no son las únicas diferencias que hemos obtenido respecto a la peligrosidad de los juegos. Como ocurría en el caso de la opinión global sobre los juegos de rol, de nuevo la edad parece que se relaciona con la percepción de peligrosidad de los juegos, y es que los adolescentes (estudiantes de secundaria) los consideran significativamente menos peligrosos cuando comparamos sus respuestas con las de los estudiantes universitarios.

Un aspecto que ha sido debatido en diversos medios hace referencia a la edad a la que se puede empezar a jugar a rol. Se considera que las consecuencias negativas de los juegos afectan sobre todo a niños y adolescentes, al ser más influenciables que los adultos. Las edades de nuestra muestra indican que los encuestados son adolescentes o jóvenes universitarios, y entre ellos la opinión mayoritaria es que la edad adecuada de

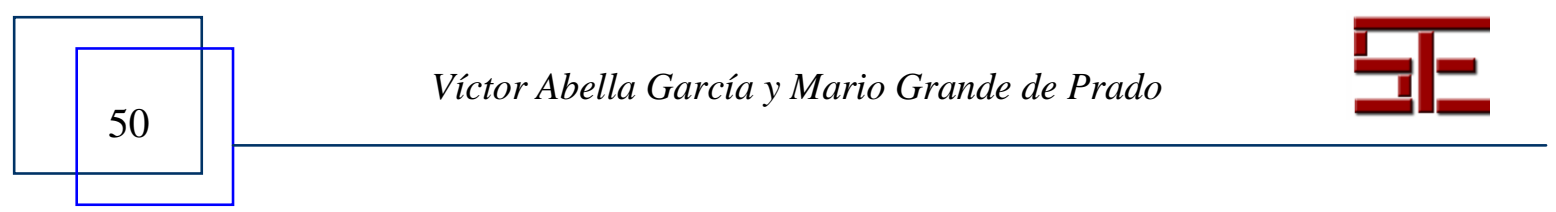




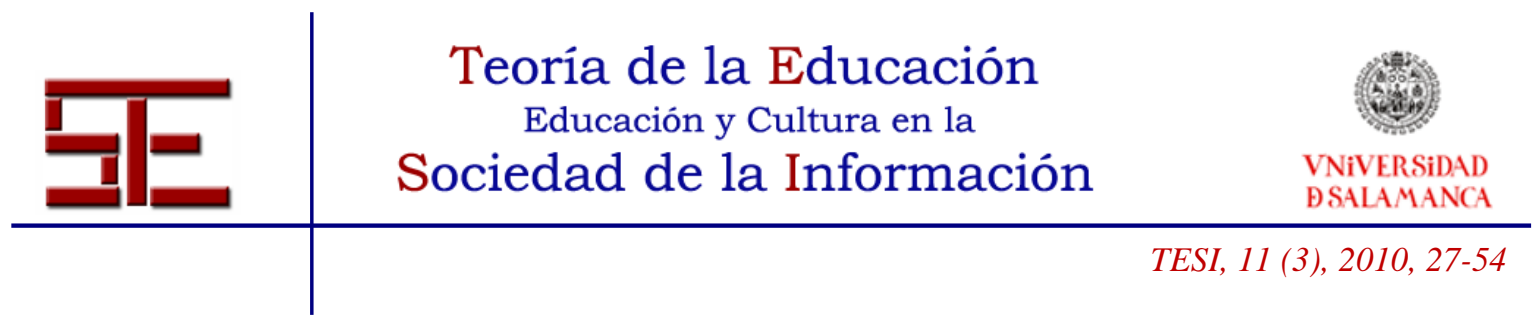

comienzo de juego debe coincidir con la mayoría de edad. Pero con respecto a esta cuestión, la opinión entre universitarios y estudiantes de secundaria vuelve a diferir de forma significativa. Los estudiantes de secundaria consideran de forma mayoritaria que se puede comenzar a jugar antes de los 18 años, mientras que los universitarios opinan mayoritariamente que la edad de comienzo debe ser los 18 años. Tanto en el estudio realizado para el Defensor del Menor de Madrid (Jodar y Vecina, 1999), como para los más críticos con los juegos de rol (San Sebastián y San Sebastián, 2004), los jugadores de rol deberían alcanzar al menos los 12 años, con lo que los universitarios parecen mostrarse extremadamente conservadores en ese aspecto. En algunas investigaciones, se han utilizado los juegos de rol con fines educativos con niños menores de doce años (Zayas y Lewin, 1986) y como detalle anecdótico, probablemente todo el mundo ha visto jugar a rol a niños de corta edad... en el cine, en concreto en una escena de la película E.T. De todas formas es evidente que sólo se pueden tratar con profundidad algunos temas con jugadores de mayor edad (y, de hecho, algunos juegos están recomendados por su temática para jugadores maduros, "mature", como la línea Black Dog de la editorial americana White Wolf).

Los medios de comunicación han dado diferentes estereotipos asociados a los juegos de rol, tildándolos de causar conductas antisociales o criminales, lo que parece entrar en contradicción con los estudios realizados (v. g. Abyeta y Forest, 1991; Simon, 1987; 1998), incluso se han asociado diferentes estereotipos a los jugadores de rol, como por ejemplo que son personas aisladas, emocionalmente inmaduras o que posen personalidades patológicas. Nuestros resultados han mostrado que la mayoría de los encuestados consideran que en muchas ocasiones esos estereotipos son ciertos, a pesar de que en numerosos estudios se ha demostrado que son erróneos (v. g. Carter y Lester, 1998; Rosenthal et al., 1998). En esta línea, también hemos constatado que el $80 \%$ de los sujetos creen que en muchas ocasiones es real la imagen, casi siempre negativa, mostrada por los medios de comunicación. Con respecto a esta cuestión hemos obtenido una asociación entre el sexo y cómo creen que los medios tratan a los juegos de rol, y es que los hombres consideran que la imagen mostrada por los medios a veces es la real en un $62 \%$, mientras que en el caso de las mujeres este porcentaje asciende al $87 \%$. Las diferencias también se manifiestan en la opinión en que consideran que esa imagen casi nunca es real, opinión que comparten el $32 \%$ de los varones, mientras que en el caso de las mujeres es del $10 \%$.

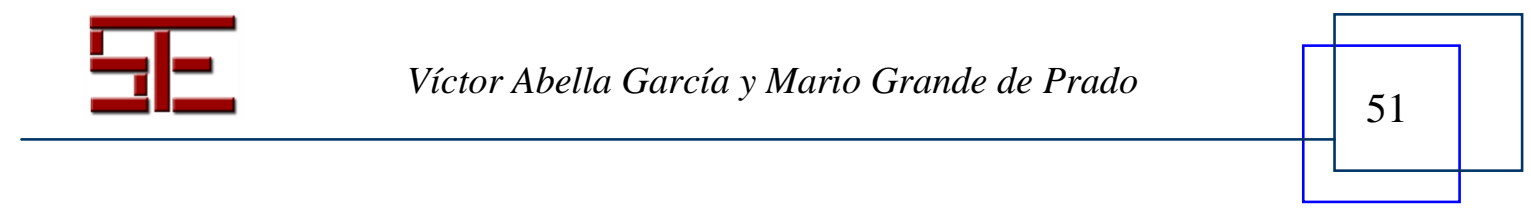




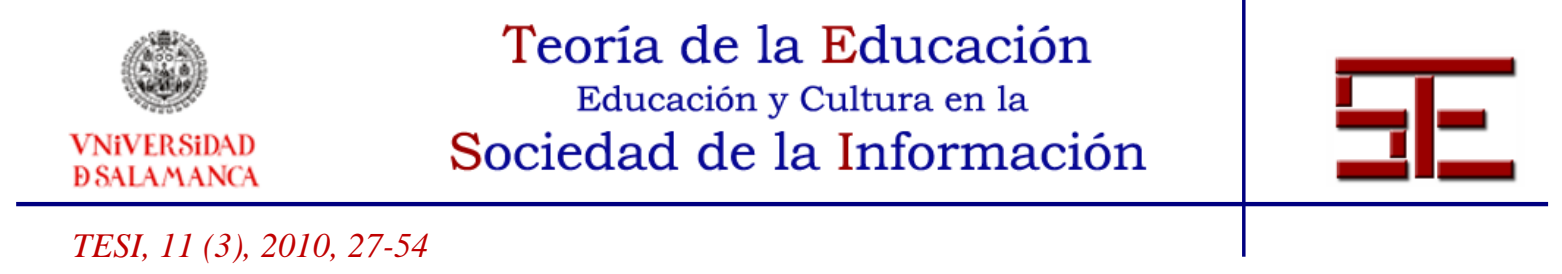

Una de las cuestiones más novedosas en el estudio es que se preguntó a los participantes sobre las posibilidades que veían a los juegos de rol en educación. Sólo un pequeño porcentaje considera que los juegos de rol pueden ser aplicables en la educación, siendo la opinión mayoritaria (61\%) los que consideran que los juegos son poco o nada aplicables a situaciones de enseñanza-aprendizaje. Sólo hemos encontrado diferencias significativas entre los que han jugado a rol y los que no lo han hecho. Tal y como cabe esperar los que han jugado a rol consideran que las posibilidades de aplicar los juegos en educación son altas, mientras que los que no han jugado consideran mayoritariamente que los juegos de rol no son útiles desde el punto de vista educativo.

A tenor de lo expuesto, parece interesante proponer para futuras investigaciones talleres de formación sobre juegos de rol para comprobar si los futuros docentes consideran que dichas actividades pueden constituirse en recurso que quieran emplear y si las ideas preconcebidas sobre los JdR se ajustan a la realidad.

\section{5.- BIBLIOGRAFÍA}

Abyeta, S. y Forest, J. (1991). Relationship of role-playing games to self-reported criminal behaviour. Psychological Reports, 69, 1187-1192.

Ascherman, L. I. (2009). The impact of unestructured games of fantasy and role-playing on an inpatient unit for adolescents. International Journal of group psychotherapy, 43, 335-344.

Amante, L. (2003). Sondeo de opinión sobre prácticas roleras en la provincia de Murcia. Extraído el 20 abril, 2009, de

http://dreamers.com/defensadelrol/articulos/investigacion.htm

Calleja, S. (1995). Juegos de Rol y Literatura. CLIJ, Cuadernos de Literatura Infantil y Juvenil, 73, 7-17.

Carter, R. \& Lester, D. (1998). Personalities of players of Dungeons and Dragons. Psychological Reports, 82, 182.

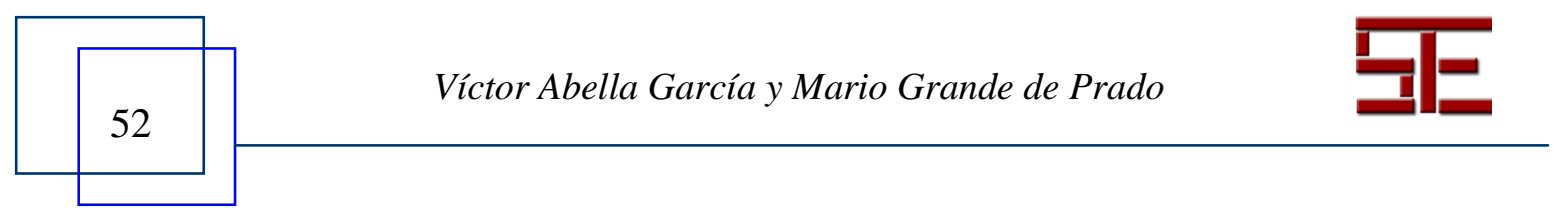




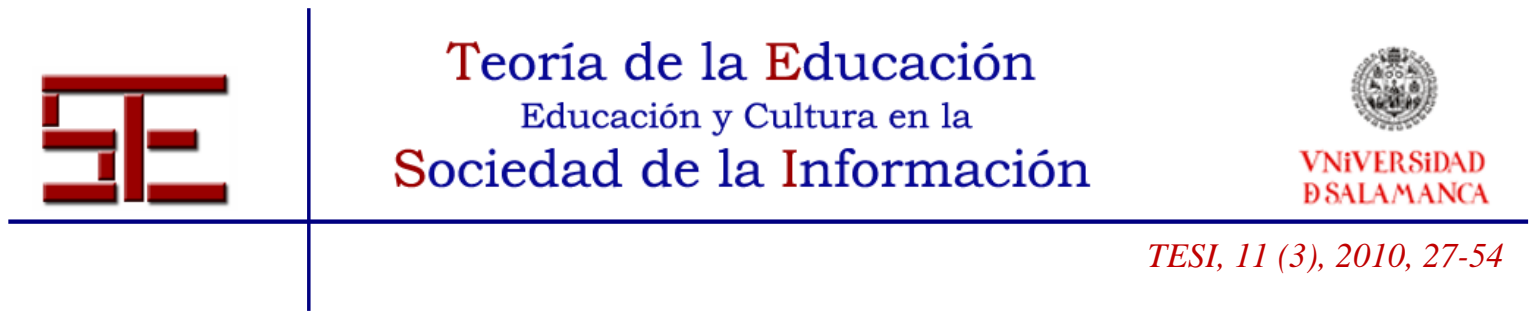

Derenard, L. \& Kline, L. (1990). Alienation and the game Dungeons and Dragons. Psychological Reports, 66, 1219-1222.

Douse, N.A. \& McManus I. C, (1993). The Personality of Fantasy Game Players. British Journal of Psychology, 84, 505-509.

Editorial de El País (2009). Crímenes sin sentido. El País, 13 de marzo.

García de la Cruz, E. (2009). En defensa de los juegos de rol. Extraído el 20 abril, 2009 de http://dreamers.com/defensadelrol/.

Giménez, P. (2003). Hacia una propuesta pedagógica de los juegos de rol. Primeras noticias. Revista de literatura, 195, 81-84.

Hitchen, M. y Drachen, A. (2009). The Many Faces of Role-Playing Games. International Journal of Role-Playing. Extraído de http://journalofroleplaying.org

Holinsworth, M. (1995). Walk a mile in someone else's shoes. Interactive Fantasy 4, 52-58.

Homo Ludens. Definición de juegos de rol (2001). www.homo-ludens.com (Consultado el 10 de diciembre de 2002, actualmente web no disponible). Disponible la mayor parte de dicho material online en http://homoludens.iespana.es/ (Consultado el 1 de mayo de 2009).

Hübner, M. (1995). Fantasy-Rollenspiel - ein kreative Medium zur Gewaltprävention? München: Aktion Jungendschutz.

Jodar, A. E. y Vecina Jiménez, M. L. (1999). Efectos psicológicos de los juegos del rol en el desarrollo social y cognitivo de los menores. En V.V.A.A. Estudios $e$ investigaciones (505-543). Madrid: Defensor del Menor de la Comunidad de Madrid.

Malcolm, A. (1994). Role-playing and dyslexia. Interactive Fantasy, 2, 109-112.

MEC (2009). Los juegos de rol. Extraído de:

http://www.isftic.mepsyd.es/w3/recursos2/estudiantes/ocio/op_03.htm\#03

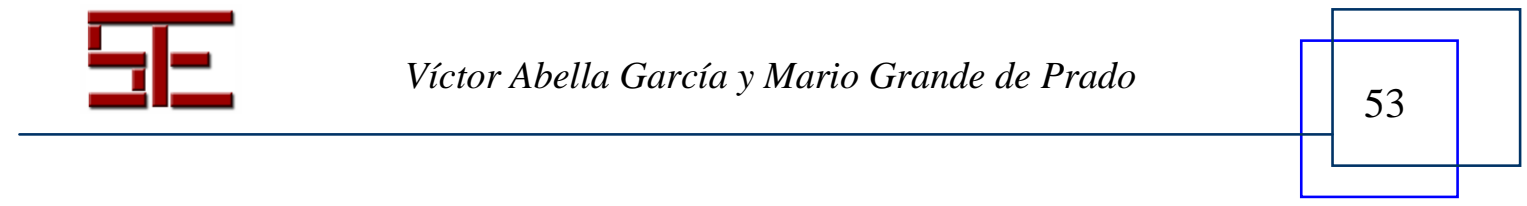




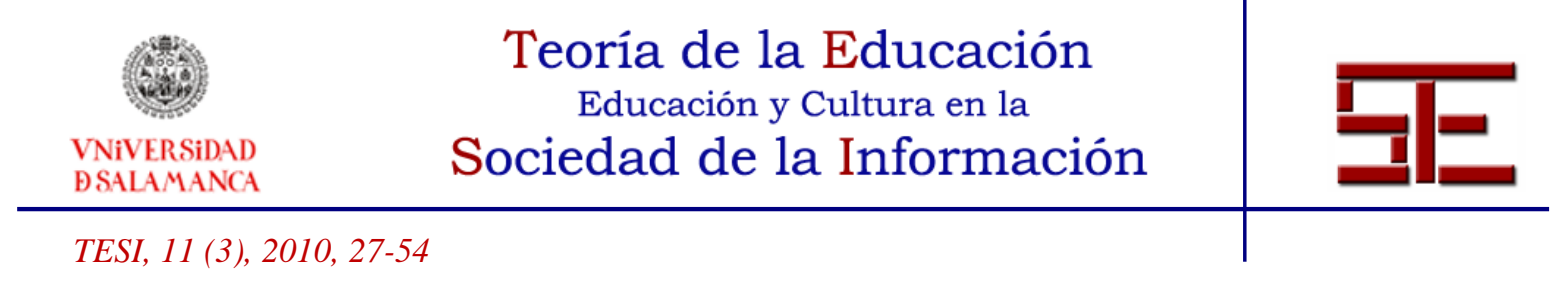

Montesinos, J. (2007). Opinión. Metro, 21 de marzo de 2007.

Oliver, M. (1995). Circle stands unbroken. Interactive Fantasy, 4, 59-67.

Ortiz Castells, J. (1999). Juegos de rol e identidades inventadas. Cuadernos de Pedagogía, 285, 61- 67.

Paulos, J. A. (1988). Innumeracy: Mathematical Illiteracy and Its Consequences. New York: Hill and Wang.

Pérez Reverte, A. (1994). Homo Ludens. El Semanal, 26 de junio de 1994.

Phillips, B. D. (1995). Foreign language education and role-playing games. Interactive Fantasy, 3, 96-103.

San Sebastián, I. y San Sebastián, J. (2004). ¿A qué juegan nuestros hijos? Madrid: La Esfera de los Libros.

Rosenthal, G. T., Soper, B., Folse, E. J. y Whipple, G. J. (1998). Role-play gamers and national guardsmen compared. Psychological Reports, 82, 169-170.

Simon, A. (1987). Emotional stability pertaining to the game of Dungeons \& Dragons. Psychology in the Schools, 24 (4) 329-332.

- (1998). Emotional stability pertaining to the game of Vampire: the Masquerade. Psychological Reports, 83, 732-734.

STS 632/1998, Caso Rosado de 25-06-1998. Extraído el 1 mayo 2009 de http://dreamers.com/defensadelrol/articulos/sentencia.htm

Tizón, R. (2006). Creer lo increíble: Mitos y verdades sobre los juegos de rol. Madrid: NSR.

Zayas, L. H. y Lewis, B. H. (1986). Fantasy role-playing for mutual aid in children's group: a case illustration. Social Work with Groups, 8, 53-66.

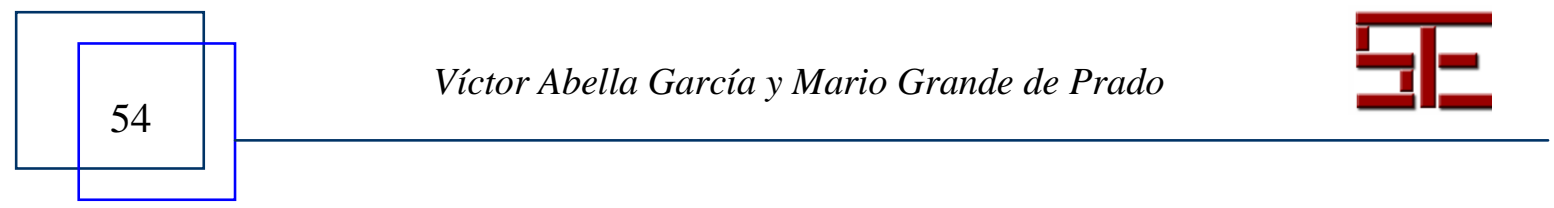




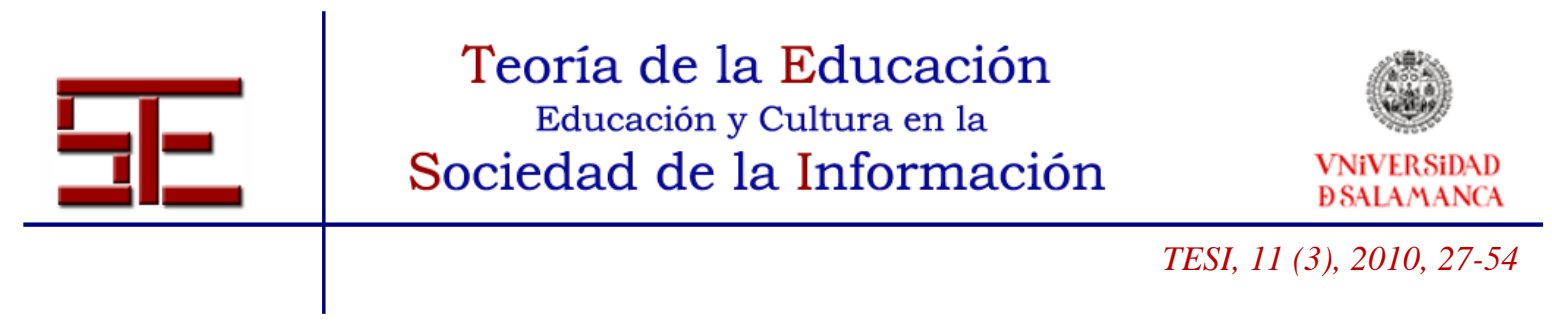

Para citar el presente artículo puede utilizar la siguiente referencia:

Abella García, V. y Grande de Prado, M. (2010). Juegos de rol como estrategia educativa: percepciones de docentes en formación y estudiantes de secundaria, en Orejudo González, J.P. (Coord.) Perspectiva educativa y cultural de "juego de rol". Revista Teoría de la Educación: Educación y Cultura en la Sociedad de la Información. Vol. 11, $\mathrm{n}^{\circ}$ 3. Universidad de Salamanca, pp. 27-54 [Fecha de consulta: dd/mm/aaaa]. http://campus.usal.es/ revistas_trabajo/index.php/revistatesi/article/view/7449/7465

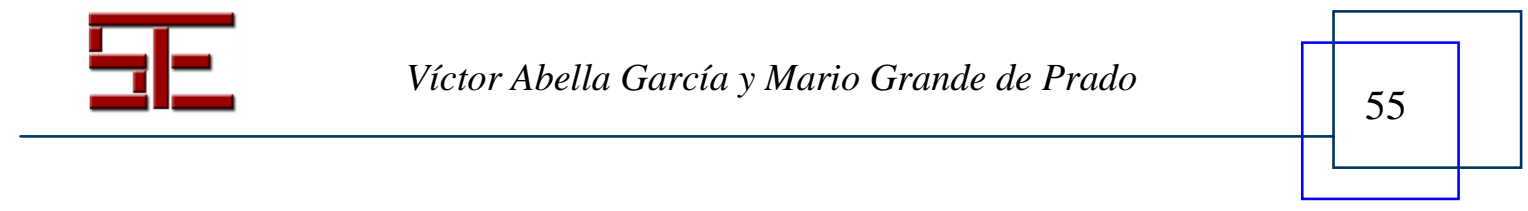

